\author{
UNIVERSIDADE DE SÃO PAULO \\ ESCOLA DE ENFERMAGEM DE RIBEIRÃO PRETO
}

ELIZABETH BARICHELLO

\title{
DISTÚRBIOS NO PADRÃO DO SONO EM PACIENTES SUBMETIDOS À CIRURGIA ONCOLÓGICA
}

RIBEIRÃO PRETO (SP) 


\section{DISTÚRBIOS NO PADRÃO DO SONO EM PACIENTES SUBMETIDOS À CIRURGIA ONCOLÓGICA}

Tese apresentada ao Programa de PósGraduação em Enfermagem Fundamental da Escola de Enfermagem de Ribeirão Preto da Universidade de São Paulo para obtenção do título de Doutora em Enfermagem

Linha de pesquisa: Processo de cuidar do adulto com doenças agudas e crônicodegenerativas.

Orientadora: Profa. Dra. Márcia Maria Fontão Zago 


\section{AUTORIZO A REPRODUÇÃO E DIVULGAÇÃO TOTAL OU PARCIAL DESTE TRABALHO POR QUALQUER MEIO CONVENCIONAL OU ELETRÔNICO PARA FINS DE ESTUDO E PESQUISA, DESDE CITADA A FONTE.}

Dados Internacionais de Catalogação na Publicação - CIP (Brasil) Catalogação na Fonte

\footnotetext{
Barichello, Elizabeth

B239d Distúrbios no padrão do sono em pacientes submetidos à cirurgia oncológica / Elizabeth Barichello. -- 2008 $114 \mathrm{f}$. : il.

Orientadora: Profa. Dra. Márcia Maria Fontão Zago Tese (doutorado em Enfermagem) - Escola de Enfermagem de Ribeirão Preto - Universidade de São Paulo, Ribeirão Preto (SP), 2008

1. Enfermagem. 2. Distúrbios do sono. 3. Qualidade de vida. 4. Sinais e Sintomas. I. Título.
} 


\section{ELIZABETH BARICHELLO}

\section{Distúrbios no padrão do sono em pacientes submetidos à cirurgia oncológica}

Tese apresentada ao Programa de PósGraduação em Enfermagem Fundamental da Escola de Enfermagem de Ribeirão Preto da Universidade de São Paulo para obtenção do título de Doutora em Enfermagem

Área de concentração: Enfermagem Fundamental.

Aprovada em: ______ de 2008

\section{BANCA EXAMINADORA}

Profa. Dra. Márcia Maria Fontão Zago

Instituição:

Assinatura:

Prof. Dr.

Instituição:

Assinatura:

Prof. Dr.

Instituição:

Assinatura:

Prof. Dr.

Instituição:

Assinatura:

Prof. Dr.

Instituição:

Assinatura: 
Aos meus pais, Antônio e Aparecida, pelo amor e constante apoio e por nunca terem medido esforços para me socorrerem em todas as fases da minha vida. Este estudo é uma conquista nossa. 


\section{AGRADECIMENTOS}

A Deus e a Nossa Senhora pelas incontáveis bênçãos concedidas durante os anos de minha vida.

À Profa. Dra. Márcia Maria Fontão Zago pela competência, carinho, compreensão e ensinamentos como orientadora e amiga desde a minha graduação. Muito obrigada!

À Profa. Dra. Namie Okino Sawada e a Profa. Dra. Helena Megumi Sonobe pelo auxílio, incentivo e apoio no desenvolvimento deste estudo.

Às amigas Lizandra Ohata, Luciana Barbosa, Simone Optz e Thais Gozzo pela amizade incondicional durante todos esses anos.

A amiga "articulada" Márcia Palhares sempre atenta e disposta a ajudar o próximo.

À Bethania Goulart, Elizabeth Lopes, Fernanda Zuffi, Helena Iwamoto, Jesislei Teixeira, Kátia Aparecida, Maria Helena Barbosa, Marina Rezende e Suzel Chavaglia pela amizade e companheirismo.

Aos colegas do Curso de Graduação em Enfermagem (UFTM), pela força e carinho.

Aos meus irmãos Carlos e Débora que mesmo distantes nunca deixaram de acreditar em mim e a Daniel (In Memorian) que nos deixou durante o percurso deste estudo.

À Sueli Riul da Silva, Ana Lúcia de Assis Simões, Márcia Tasso Dal Poggetto e Rejane Cussi Assunção Lemos pela colaboração dispensada.

A todos vocês, muito obrigada! 
"Comece fazendo o que é necessário, depois o que é possível, em breve estarás fazendo o impossível."

São Francisco de Assis. 


\section{RESUMO}

BARICHELLO, E. Distúrbios no padrão do sono em pacientes submetidos à cirurgia oncológica, 2008. $114 \mathrm{f}$. Tese (Doutorado) - Escola de Enfermagem de Ribeirão Preto da Universidade de São Paulo, Ribeirão Preto, 2008.

Introdução: distúrbios no padrão do sono são sintomas comuns em pacientes com câncer e a literatura pertinente é escassa. Sabe-se que suas conseqüências são fortemente relacionadas à qualidade de vida dos sobreviventes do câncer. Objetivo: avaliar o padrão do sono em pacientes cirúrgicos oncológicos após a alta hospitalar e relacioná-lo com as dimensões da qualidade de vida. Método: estudo de pesquisa exploratória com delineamento observacional-transversal, realizado em 46 pacientes com diagnóstico de câncer, submetidos a procedimento cirúrgico nas especialidades de cabeça e pescoço e de urologia, no período de um até o sexto mês de pósoperatório. As entrevistas foram realizadas no ambulatório da Associação de Combate ao Câncer do Brasil Central, localizada na cidade de Uberaba - MG, após assinatura do termo de consentimento. Para obtenção dos dados foram utilizados três questionários: instrumento $A$, para obter características sociais e clínicas dos pacientes; Índice de Qualidade do Sono de Pittsburg - PSQI, utilizado na mensuração da qualidade subjetiva do sono e para a ocorrência de seus distúrbios; European Organization for Research and Treatment of Cancer Quality of Life Questionnaire "Core" 30 itens (EORTC-QLQ-C30), para abordar os aspectos relacionados com a qualidade de vida no câncer. A consistência interna das escalas do PSQI e do EORTC foi verificada por meio do Coeficiente Alfa de Cronbach. Para este estudo, adotou-se $p$ value inferior a 0,05 como estatisticamente significante. Resultados e Discussão: os procedimentos cirúrgicos na área de Cabeça e Pescoço corresponderam a $30,4 \%$ (14) dos pacientes e os da Urologia, a $69,6 \%$ (32). A confiabilidade alfa de Cronbach da escala do PSQI e do EORTC foi 0,794 e 0,8139 , respectivamente. A correlação de Pearson entre o Estado Geral de Saúde (EGS) do EORTC e o escore global do PSQI foi $r=-0,339$ e entre o escore global do $P S Q I$ e o domínio de insônia do EORTC, de $r=0,710$. Em relação às respostas fornecidas pelos entrevistados, observou-se: $73,9 \%$ possuem comprometimento da qualidade subjetiva do sono; os itens estatisticamente significantes para os dados sociodemográficos e clínicos, em relação ao escore global do PSQI, foram a renda, a escolaridade e o local do câncer; para os domínios do EORTC, em relação ao escore global do PSQI, foram o EGS, desempenho de papel, função social, dispnéia, fadiga, insônia e dificuldade financeira. Considerações: distúrbios no padrão do sono são freqüentes em sobreviventes do câncer e aceita-se que geralmente levam a problemas crônicos, que interferem diretamente na qualidade de vida. Espera-se que este estudo sensibilize a equipe de enfermagem, quanto à necessidade de investigar possíveis causas para distúrbios no padrão do sono em sobreviventes e conseguir implementar cuidados necessários para garantir melhor qualidade de vida.

Palavras-chave: Enfermagem. Distúrbios do sono. Qualidade de vida. Sintomas. 


\section{RESUMEN}

BARICHELLO, E. Disturbios en el padrón del sueño en pacientes sometidos a la cirugía oncológica, 2008. 114 f. Tese (Doctorado) - Escuela de Enfermería de Ribeirão Preto de la Universidad de São Paulo, Ribeirão Preto, 2008.

Introducción: disturbios en el padrón del sueño son síntomas comunes en pacientes con cáncer y la literatura pertinente es escasa. Se sabe que sus consecuencias son fuertemente relacionadas a la cualidad de vida de los sobrevivientes del cáncer. Objetivo: evaluar el padrón del sueño en pacientes quirúrgicos oncológicos después de la alta hospitalaria y relacionarlo con las dimensiones de la cualidad de vida. Método: estudio de pesquisa exploratoria con delineamiento observacional-transversal, realizado en 46 pacientes con diagnóstico de cáncer, sometidos a procedimiento quirúrgico en las especialidades de cabeza y cuello y de urología, en el período de un hasta el sexto mes de pos-operatorio. Las entrevistas fueron realizadas en el ambulatorio de la Asociación de Combate al Cáncer del Brasil Central, localizada en la ciudad de Uberaba - MG, pos asignatura del término de consentimiento. Para obtención de los datos fueron utilizados tres cuestionarios: instrumento A, para obtener características sociales y clínicas de los pacientes; Índice de Cualidad del Sueño de Pittsburg - PSQI, utilizado en la mensuración de la cualidad subjetiva del sueño y para la ocurrencia de sus disturbios; European Organization for Research and Treatment of Cancer Quality of Life Questionnaire "Core" 30 itens (EORTC-QLQ-C30), para abordar los aspectos relacionados con la cualidad de vida en el cáncer. La consistencia interna de las escalas del PSQI y del EORTC fue verificada por medio del Coeficiente Alfa de Cronbach. Para este estudio, se adoptó $p$ valor inferior a 0,05 como estadísticamente significante. Resultados y Discusión: los procedimientos quirúrgicos en la área de Cabeza y Cuello correspondieron a 30,4\% (14) de los pacientes y los de la Urología, a 69,6\% (32). La confiabilidad alfa de Cronbach de la escala del PSQI y del EORTC fue 0,794 e 0,8139, respectivamente. La correlación de Pearson entre el Estado General de Salud (EGS) del EORTC y el escore global del PSQI fue $r=-0,339$ y entre el escore global del PSQI y el dominio de insomnio del EORTC, de $r=0,710$. En relación a las respuestas fornecidas por los entrevistados, se observó: 73,9\% poseen comprometimiento de la cualidad subjetiva del sueño; los ítems estadísticamente significantes para los datos sociodemográficos y clínicos, en relación al escore global del PSQI, fueron la renda, la escolaridad y el local del cáncer; para los dominios del EORTC, en relación al escore global del PSQI, fueron el EGS, desempeño de papel, función social, dispnéia, fadiga, insomnio y dificultad financiera. Consideraciones: disturbios en el padrón del sueño son frecuentes en sobrevivientes del cáncer y se acepta que generalmente llevan a problemas crónicos, que interfieren directamente en la cualidad de vida. Se espera que este estudio sensibilice el equipo de enfermería, cuanto a la necesidad de investigar posibles causas para disturbios en el padrón del sueño en sobrevivientes y conseguir implementar cuidados necesarios para garantizar mejor cualidad de vida.

Palabras-clave: Enfermería. Disturbios del sueño. Cualidad de vida. Síntomas. 


\begin{abstract}
BARICHELLO, E. Sleep pattern disturbances in postoperative surgical oncology patients, 2008. 114 f. Thesis (Doctorate) - Nursing School of Ribeirão Preto, University of São Paulo, Ribeirão Preto, 2008.

Introduction: sleep pattern disturbances are common in patients with cancer and pertinent references are scarce. It is known that their consequences are closely related to quality of life of cancer survivors. Objective: to evaluate the sleep pattern of surgical oncology patients after hospital discharge and to relate it with quality of life dimensions. Method: exploratory research with transversal-observational design, in 46 postoperative head \& neck and urology cancer patients, one to six months after the operation. Outpatient interviews were made in the Associação de Combate ao Câncer do Brasil Central, located in the city of Uberaba - MG, after obtention of signed consent form. Data were collected by use of three questionnaires: instrument A, to obtain social characteristics and patients' clinical information; Pittsburgh Sleep Quality Index - PSQI, for evaluation of subjective quality of sleep and for occurrence of sleep disturbances; European Organization for Research and Treatment of Cancer Quality of Life Questionnaire "Core" 30 itens (EORTC-QLQ-C30), to register aspects related to cancer quality of life. The internal consistency of the scales of PSQI and of EORTC was verified by means of Cronbach's Alpha Coefficient. For this study, $p$ values lower than 0.05 were considered statistically significant. Results and Discussion: surgical procedures of Head and Neck corresponded to $30.4 \%$ (14) of the patients, compared to $69.6 \%$ (32) for Urology. Cronbach's alpha reliability of the scales of PSQI and EORTC were 0.794 and 0.8139 , respectively. Pearson's Correlation between General Health Condition (EGS) of EORTC and global PSQI score was $r=-0.339$, and between global $P S Q I$ score and the insomnia domain of EORTC was $r=0.710$. Regarding the answers supplied by the interviewees, it was observed: $73,9 \%$ have impairment of the subjective quality of sleep; the statistically significant items for social and clinical data, relative to global PSQI score, were the income, the level of schooling and the location of the cancer; for the domains of EORTC, relative to global PSQI score, were EGS, daily activity performance, social function, dyspnea, fatigue, insomnia and financial difficulty. Considerations: sleep pattern disturbances are frequent in cancer survivors and it is accepted that they usually lead to chronic problems, which interfere directly with quality of life. It is expected that this study sensitizes the nursing team, regarding the need to investigate possible causes for sleep pattern disturbances in survivors and to get implemented necessary cares to guarantee better quality of life.
\end{abstract}

Keywords: Nursing. Sleep disturbances. Quality of life. Symptoms. 


\section{LISTA DE TABELAS}

Tabela 1 Caracterização da amostra segundo as variáveis sóciodemográficas e clínicas. Uberaba (MG) -2008. ( $F$ = freqüência).

Tabela 2 Caracterização da amostra segundo os domínios e os escores do EORTC. Uberaba (MG) - 2008

Tabela 3 Confiabilidade Alfa de Cronbach da escala do PSQI e do EORTC, na amostra de pacientes cirúrgicos oncológicos. Uberaba (MG) - 2008

Tabela 4 Correlação de Pearson entre o Estado Geral de Saúde (EGS) do EORTC e o Escore Global do PSQI, na amostra de pacientes cirúrgicos oncológicos. Uberaba (MG) - 2008.

Tabela 5 Correlação de Pearson entre as medidas obtidas do instrumento do Escore Global do PSQI com o domínio de Insônia do EORTC. Uberaba (MG) - 2008

Tabela 6 Freqüência e porcentagem das respostas dos sujeitos nas questões abertas do PSQI. Uberaba (MG) - 2008.

Tabela 7 Freqüência e porcentagem das respostas dos sujeitos nas questões semi-abertas do PSQI. Uberaba (MG) - 2008.

Tabela 8 Freqüência e porcentagem das respostas dos sujeitos na questão de número 10 do PSQI. Uberaba (MG) - 2008.

Tabela 9 Freqüência e porcentagem das respostas dos sujeitos em relação aos componentes do PSQI. Uberaba (MG) - 2008.

Tabela 10 Escore Global do Índice de Qualidade do Sono (PSQI), em pacientes com diagnóstico de câncer, que foram submetidos a procedimento cirúrgico nas especialidades de Cabeça e Pescoço e de Urologia, no período de um até o sexto mês de pós-operatório. Uberaba (MG) - 2008.

Tabela 11 Média, desvio padrão e significância estatística dos componentes do PSQI em relação ao Escore Global do PSQI. Uberaba (MG) - 2008

Tabela 12 Média, desvio padrão e significância estatística das variáveis sociodemográficas e clínicas, em relação ao Escore Global do PSQI. Uberaba (MG) - 2008

Tabela 13 Média, desvio padrão e significância estatística dos domínios do EORTC, em relação ao Escore Global do PSQI. Uberaba (MG) -2008 


\section{LISTA DE ABREVIATURAS}

$\begin{array}{ll}\text { ONS } & \text { Oncology Nursing Society } \\ \text { INCA } & \text { Instituto Nacional do Câncer } \\ \text { NCCS } & \text { National Coalition for Cancer Survivorship } \\ \text { REM } & \text { Rapid Eye Moviment } \\ \text { NREM } & \text { Non Rapid Eye Moviment } \\ \text { PSQI } & \text { Índice de Qualidade do Sono de Pittsburg } \\ \text { EORTC-QLQ-C30 } & \text { European Organization for Research and Treatment of } \\ & \text { Cancer Quality of Life - Questionnaire "Core" 30 itens } \\ \text { SPSS } & \text { Statistical Package for the Social Sciences } \\ \text { EGS } & \text { Estado Geral de Saúde } \\ \text { IL-1 } & \text { Interleucina 1 } \\ \text { ANOVA } & \text { Teste paramétrico de Análise da Variância } \\ \text { DP } & \text { Desvio padrão }\end{array}$




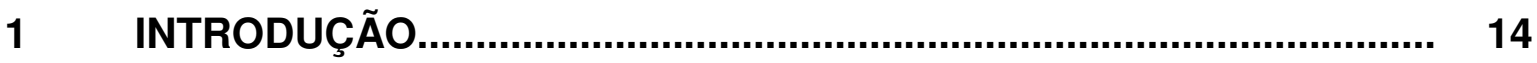

1.1 O CÂNCER E OS TRATAMENTOS ..................................................... 16

1.1.1 Cirurgia oncológica................................................................. 18

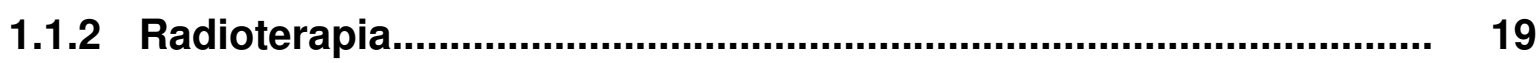

1.1.3 Quimioterapia..................................................................... 21

2 REFERENCIAL TEÓRICO: O SONO E OS SEUS ESTÁGIOS............ 24

2.1 IMPLICAÇÕES DA PRIVAÇÃO DO SONO PARA OS PACIENTES ONCOLÓGICOS....................................................................... 29

2.2 O PAPEL DO ENFERMEIRO NA AVALIAÇÃO E CONTROLE DO SONO DO PACIENTE ONCOLÓGICO................................................. 33

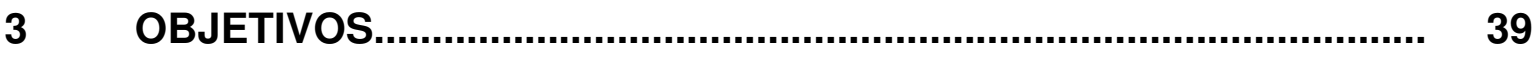

3.1 OBJETIVO GERAL................................................................ 40

3.2 OBJETIVOS ESPECÍFICOS......................................................... 40

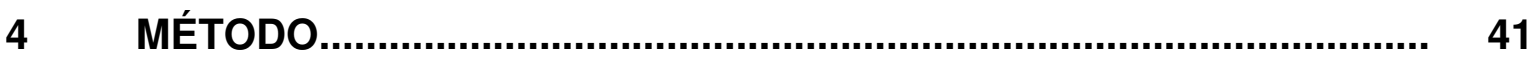

$4.1 \quad$ TIPO DE ESTUDO.............................................................. 42

4.2 POPULAÇÃO E AMOSTRA ............................................................. 43

4.3 LOCAL E PERÍODO......................................................................... 44

4.4 PROCEDIMENTOS ÉTICOS............................................................. 45

4.5 INSTRUMENTOS DE COLETA DE DADOS....................................... 45

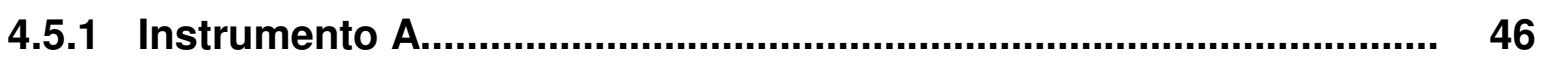

4.5.2 Índice de Qualidade de Sono de Pittsburg - PSQI........................ 47

4.5.3 European Organization for Research and Treatment of Câncer Quality of Life Questionnaire "Core" 30 itens (EORTC-QLQ-C30).. 48

4.6 ANÁLISE ESTATÍSTICA DOS DADOS ............................................ 49

4.6.1 Métodos para validação dos instrumentos de Avaliação da Qualidade de Vida................................................................ 49

4.6.2 Verificação da associação entre as escalas do PSQI com as variáveis sociais e clínicas.

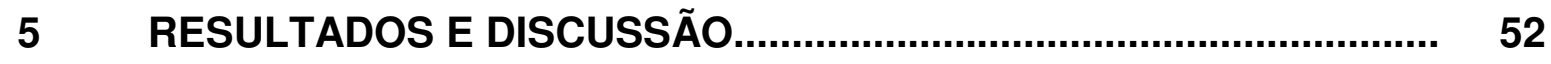

5.1 CARACTERIZAÇÃO DA AMOSTRA E APLICAÇÃO DOS TESTES DE CONFIABILIDADE E CORRELAÇÃO.

5.2 CARACTERIZAÇÃO DO ÍNDICE DE QUALIDADE DO SONO DE PITTSBURGH - PSQI.

5.3 ANÁLISES ENTRE OS QUESTIONÁRIOS APLICADOS NA AMOSTRA... 
6 CONCLUSÕES....................................................................... 83

REFERÊNCIAS...................................................................... 86

APÊNDICES........................................................................ 94

APÊNDICE A - Carta de Solicitação................................................... 95

APÊNDICE B - Termo de Consentimento Livre e Esclarecido.............. 96

APÊNDICE C - Instrumento A: variáveis sociais e clínicas................... 98

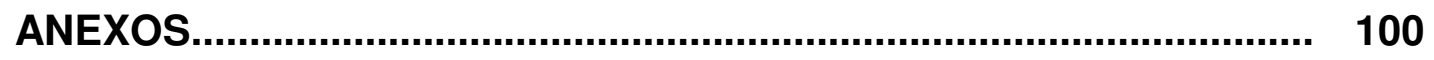

ANEXO A - Parecer Comitê de Ética da UFTM................................... 101

ANEXO B - Índice de Qualidade do Sono de Pittsburgh - PSQI.......... 104

ANEXO C - Índice de Qualidade do Sono de Pittsburg - Instruções de pontuação

ANEXO D - European Organization for Research and Treatment of Cancer Quality of Life Questionnaire "Core" 30 itens. (EORTC-QLQC30).

ANEXO E - Escore e Pontuação do EORTC........................................ 113 


\section{INTRODUÇÃO}


Os cuidados prestados ao paciente com câncer são decorrentes de um empenho multidisciplinar, no qual a enfermagem exerce um papel fundamental, pois é o grupo profissional que mantém contato com o paciente e sua família em todos os períodos da trajetória da doença e em diferentes contextos de atendimento. Porém, para poder fornecer um cuidado com qualidade, é preciso que o enfermeiro demonstre conhecimento das dimensões biológicas e fisiológicas da doença, dos tratamentos e do impacto que estes ocasionam na vida dos pacientes e seus familiares. Assim, a enfermagem é responsável em detectar, intervir e avaliar os sinais e sintomas da doença, bem como os efeitos dos tratamentos nos pacientes.

Nossa preocupação com a temática originou-se após a análise das Agendas de Pesquisa da Oncology Nursing Society (ONS), para 2003 a 2005 e 2005 a 2009 (ONS, 2003; 2007), que destacaram as conseqüências dos distúrbios do sono para a qualidade de vida dos sobreviventes do câncer como uma temática pouco estudada e, conseqüentemente, compreendida. Com isso, a ONS lançou este desafio para as enfermeiras pesquisadoras, a fim de que possam ser avaliados os distúrbios do sono e suas conseqüências para a reabilitação do paciente e garantir uma intervenção segura e melhor qualidade de vida. Os distúrbios no padrão do sono, no paciente com câncer, passam a ser uma prioridade para a pesquisa em enfermagem, pois é um dos fatores responsável pelo sintoma da fadiga (BURKE, 2006).

Hoje a literatura traz um novo modelo conceitual para a área da assistência em oncologia, o dos "sobreviventes do câncer", proposto pelo National Coalition for Cancer Survivorship (NCCS) em 2004. Segundo essa instituição, o sobrevivente é o indivíduo que foi diagnosticado com câncer; a sobrevivência é o período que vai 
desde a confirmação do diagnóstico, perpassa pela fase dos tratamentos e continua até que haja o equilíbrio de vida ou ocorra a morte (FISHER, 2006).

Esse modelo reconhece que devido ao período alongado da sobrevivência dos pacientes, a atenção volta-se para a sua qualidade de vida. Contrapondo-se a esse aspecto, as pesquisas médicas e de enfermagem apontam que, embora hoje haja uma redução da mortalidade durante e após os tratamentos para a doença, surgem sintomas múltiplos, como fadiga, dor, redução do apetite, disfunções cognitivas e sexuais, constipação e distúrbios do sono, que interferem no retorno às atividades cotidianas, isto é, na sua qualidade de vida (HAYLOCK et al., 2007).

Nesse contexto, o estudo tem a finalidade de contribuir para assistência de enfermagem, focalizando a avaliação do padrão do sono de sobreviventes do câncer.

\subsection{O CÂNCER E OS TRATAMENTOS}

Segundo o Instituto Nacional de Câncer - INCA, no Brasil, a incidência do câncer cresce no mesmo ritmo que o envelhecimento populacional decorrente do aumento da expectativa de vida. Para o ano de 2006, houve uma ocorrência de 472 mil casos novos de câncer no país e o registro de 141 mil óbitos. Em 2005, o SUS registrou 423 mil internações por neoplasias malignas e 1,6 milhão de consultas ambulatoriais em oncologia. Embora tenha ocorrido um aumento de atendimentos de pacientes com câncer nas unidades do SUS, o INCA reconhece que ainda há dificuldades em algumas especialidades, de articulação entre as unidades da rede e 
a inexistência de resultados positivos na saúde da população. Para o ano de 2008, são esperados 231.860 casos novos para o sexo masculino e 234.870 para o feminino. Estima-se que o câncer de pele do tipo não melanoma será o mais incidente na população do país, seguido pelos tumores de próstata, de mama feminina, de pulmão, de cólon e reto, de estômago e de colo de útero (BRASIL, 2007).

Um aspecto importante destacado pelo INCA é de que o câncer é um problema de saúde pública no país, pois, há aumento da prevalência de cânceres associados ao melhor nível socioeconômico (mama, próstata, cólon e reto) e também os associados à pobreza (colo de útero, pênis, estômago e cavidade oral). Segundo o instituto, os tratamentos - cirurgia, quimioterapia e radioterapia - são componentes do programa nacional de controle do câncer, e suas metas são a cura, o prolongamento da vida útil e melhora da qualidade de vida (BRASIL, 2007).

Para o Estado de Minas Gerais e a cidade de Belo Horizonte, o Brasil (2007) estima a incidência de 5.050 casos de câncer de próstata e 4.280 casos de câncer de mama feminina, sendo esses dois tipos de neoplasia os mais incidentes na região. No estado, a doença tem um índice de mortalidade de 81,89 mortes para cada 100 mil habitantes (BRASIL, 2007), o que denota a preocupação com o controle da doença e dos sobreviventes no estado.

Os princípios básicos do tratamento do câncer fundamentam-se em fatores que influenciam o prognóstico, isto é: o estadiamento do tumor no momento do diagnóstico, as características biológicas do tumor, o planejamento terapêutico e o estado geral do paciente. Os objetivos dos tratamentos para o câncer são: diminuir a possibilidade de recorrência local e a distância; transformar tumores irressecáveis em ressecáveis; agir nas células neoplásicas circulantes, nas micrometástases e nas 
metástases detectadas; aumentar as taxas de cura e de sobrevida; e melhorar a qualidade de vida (VARRICCHIO, 2004).

As modalidades terapêuticas do câncer são classificadas como:

a) loco-regionais (cirurgia e radioterapia);

b) sistêmicas (quimioterapia, hormonioterapia e imunoterapia);

c) reabilitação (física e psicológica).

As terapêuticas mais recomendadas e empregadas são a cirurgia, a quimioterapia e a radioterapia.

\subsubsection{Cirurgia oncológica}

A cirurgia é um dos principais tratamentos para o câncer; $60 \%$ dos pacientes são tratados cirurgicamente. De um modo geral, os tumores de crescimento lento são os melhores candidatos à cirurgia, e a cirurgia inicial para câncer tem maior chance de cura que a cirurgia para recidivas (VARRICCHIO, 2004).

Além dos cuidados normais de assepsia e hemostasia para todas as cirurgias, as cirurgias para tratamento de câncer apresentam algumas particularidades. Por exemplo, deve-se sempre manipular os tumores com cuidado, para evitar que células cancerosas ganhem a corrente sanguínea e causem metástases (VARRICCHIO, 2004).

A presença de margens cirúrgicas livres é outro ponto fundamental em cirurgia oncológica, sendo que todo tumor deve ser retirado com uma margem de tecido normal ao redor, para evitar que células microscópicas causem recidiva e, 
sempre que indicado, deve-se retirar os linfonodos adjacentes devido ao risco de metástases regionais ou linfáticas (VARRICCHIO, 2004).

Todo material retirado em cirurgia tem que ser enviado para exame anátomo-patológico. Mesmo em cirurgias menores, que a princípio podem não ser consideradas oncológicas, o exame microscópico pode mostrar o contrário. Em cirurgia oncológica, o exame anátomo-patológico é essencial para determinar as margens cirúrgicas (VARRICCHIO, 2004).

Assim, a intervenção cirúrgica para o tratamento do câncer tem vários propósitos, incluindo a confirmação do diagnóstico e do estadiamento, de cura, de prevenção, como tratamento paliativo e o de reconstrução (VARRICCHIO, 2004).

Os procedimentos cirúrgicos nos cânceres com finalidade curativa podem ser subdivididos em conservadores ou radicais. A conservadora visa preservar a função e a parte estética; a radical visa remover o tumor, com margem de segurança, provocando mutilações importantes para a vida do paciente (SPENCE; JOHNSTON, 2003).

Muitos tumores podem ser tratados com cirurgia exclusiva, outros com combinação de cirurgia mais radioterapia, ou ainda cirurgia, radioterapia e quimioterapia (VARRICCHIO, 2004).

\subsubsection{Radioterapia}

A radioterapia usa a radiação ionizante para o tratamento de pacientes com neoplasias malignas. Seu objetivo é administrar uma dose precisa de radiação a um 
volume tumoral definido, causando a mínima lesão possível ao tecido adjacente. Além da possibilidade de cura, a radioterapia tem papel importante na paliação ou prevenção de sintomas no câncer, como a dor (SPENCE; JOHNSTON, 2003).

Após a confirmação do diagnóstico de câncer, 50 a 70\% dos pacientes serão submetidos a radioterapia, em alguma fase da sua sobrevivência (SPENCE; JOHNSTON, 2003).

A radioterapia pode ser empregada com vários propósitos:

a) como tratamento primário (neoplasias de cabeça e pescoço, do pulmão, da próstata, da bexiga e outras);

b) como tratamento neo-adjuvante aplicado antes do tratamento definitivo para melhorar as chances de sucesso da ressecção cirúrgica (nos cânceres do esôfago e de cólon);

c) como tratamento adjuvante aplicado depois do tratamento definitivo (cirurgia ou quimioterapia) para melhorar o controle local (câncer de mama, de pulmão e do reto);

d) como profilaxia para tratar áreas assintomáticas, mas com alto risco de metástases (irradiação cranial no câncer de pulmão);

e) como controle para limitar o crescimento de células cancerosas (câncer pancreático e de pulmão);

f) como paliação para minimizar sintomas como a dor, a obstrução aérea, a dor neuropática, e outros (VARRICCHIO, 2004).

A aplicação da radioterapia pode ser externa - teleterapia - ou interna braquiterapia. A teleterapia usa fontes radioativas de origem nuclear que produzem radiação por meio da aceleração de elétrons; é a empregada na maioria das neoplasias. A braquiterapia é de curta distância, em que uma fonte encapsulada ou 
um grupo dessas fontes é usado para liberação de radiação, a poucos centímetros do tumor (VARRICCHIO, 2004).

A dose de radiação a ser administrada é determinada por vários fatores, como: a radiossensibilidade do tumor, a tolerância do tecido normal adjacente e o volume do tecido a ser irradiado. As doses de radiação são fracionadas, pois uma dose letal pode levar à uma toxicidade inaceitável ou mesmo a morte do paciente. A extensão do tratamento dependerá da localização, tamanho e tipo de célula do tumor, como também da potência das reações, no paciente (VARRICCHIO, 2004).

Os efeitos tóxicos da radioterapia se localizam na região irradiada e dependem da localização do tumor, da dose empregada, do volume do tecido irradiado, da dose total e do estado geral do paciente (VARRICCHIO, 2004).

\subsubsection{Quimioterapia}

Segundo Bonassa (2005), a quimioterapia consiste no emprego de substâncias químicas isoladas ou em combinação, com o objetivo de tratar as neoplasias malignas e é uma das principais terapêuticas para esta doença. As drogas quimioterápicas agem sistemicamente, em nível celular, especificamente em células que estão em processo de divisão celular, interferindo no seu crescimento e divisão.

A autora complementa que essas drogas são tóxicas para os tecidos de rápida proliferação e por isso são mais eficazes quando os tumores são de pequeno 
tamanho. Essa terapêutica tem sido altamente eficaz para a cura das leucemias e para o tratamento precoce das metástases não detectáveis.

As drogas quimioterápicas podem ser agrupadas conforme sua especificidade de atuação no ciclo celular ou de acordo com a função e estrutura química (BONASSA, 2005).

Em relação ao período em que o tratamento será realizado e o seu objetivo, a quimioterapia pode ser classificada em:

a) neo-adjuvante: seu objetivo é a redução tumoral, para depois tratamento local, e para redução das micrometástases;

b) adjuvante: usada após o tratamento primário com a finalidade de combater as micrometástases;

c) paliativo: usado em situações de metástases ou recidivas do câncer (BONASSA, 2005).

O emprego de esquemas poliquimioterápicos, ou a combinação de mais de uma droga com mecanismos de ação distintos, tem sido recomendado, pois podem ser empregados em doses menores, retardando o mecanismo de resistência tumoral, diminuindo os efeitos tóxicos e colaterais (BONASSA, 2005).

Entre os efeitos adversos da quimioterapia destacamos:

a) a toxicidade não hematológica, em que estão incluídas as toxicidades gastrointestinais, pulmonares, cardíacas, hepáticas, neurológicas, renais, vesicais, dermatológicas, disfunções reprodutivas, alterações metabólicas, reações alérgicas e a fadiga;

b) a toxicidade hematológica, que compreende a leucopenia, anemia, trombocitopenia e neutropenia febril (BONASSA, 2005). 
Cada droga tem um perfil de toxicidade e de efeitos colaterais, sendo importante o uso racional dos agentes. Por isso, os pacientes submetidos a essa terapêutica precisam ser monitorados para determinar a ocorrência e a duração desses efeitos (BONASSA, 2005).

Atualmente, há novos antibióticos e drogas anti-eméticas que aumentam a tolerabilidade ao tratamento quimioterápico (BONASSA, 2005).

Em oncologia é difícil avaliar a eficácia comparativa das intervenções terapêuticas. Se uma pessoa sucumbe após ser tratada, a terapia claramente foi falha. Por outro lado, a recuperação com o retorno da saúde, ganho de peso, e retomada das atividades normais da vida não são evidências conclusivas de que a cura foi obtida. Assim, em oncologia, a cura é muito mais um termo estatístico aplicado a grupos de pacientes com câncer do que a indivíduos (MAXWELL, 1997). 
2 REFERENCIAL TEÓRICO:

O SONO E OS SEUS ESTÁGIOS 
O sono é uma parte inevitável da vida do ser humano e fundamental para a manutenção das atividades diárias da vida; portanto, é um evento fisiológico importante para o organismo humano. Em 1973, Kleitman (apud LAMB, 1982, p. 389) o definiu como "uma cessação temporária freqüente ou interrupção do estado de despertar, que é o funcionamento prevalecente de existência para saúde do homem adulto". Koella (1973, apud LAMB, 1982, p. 389) ampliou esta definição e descreveu o fenômeno do sono como um "estado reversível periódico de ocorrência de redução do contato ativo e passivo de um organismo com o mundo circunvizinho". As principais funções incluídas na definição de sono são:

1. o sono suspende o complexo da atividade sensorial motora da pessoa, em relação à referência que a mesma tem ao meio em que vive;

2. o sono e a vigilância compreendem fases alternadas no ciclo de existência;

3. o sono é uma função normal corpórea exigida para manter a saúde física e mental (LAMB, 1982).

Segundo Redeker, Lev e Ruggiero (2000), o sono é multidimensional e é constituído por fenômenos padronizados e caracterizados por:

a) redução de consciência e de interação com o ambiente;

b) diminuição da motilidade e da atividade muscular;

c) pendência parcial ou completa do comportamento voluntário e do nível de consciência.

Um período suficiente de horas de sono promove saúde e auxilia os efeitos de restauração de tecido corpóreo, o sistema imune e o equilíbrio psicológico.

Existe um entendimento universal de que o distúrbio do sono é um sintoma comum entre os pacientes com câncer. Apesar disto, na literatura há poucos estudos 
que o avaliam. Isto pode ser um dos motivos pelo qual a equipe de saúde não provê intervenções efetivas para os pacientes que apresentam o distúrbio.

A fim de entender as alterações de sono em pacientes com câncer, é importante ter uma compreensão dos mecanismos relacionados ao mesmo. Há dois processos e dois tipos de sono. Os processos são designados pelas letras S e C. O processo S envolve a homeostasia do sono e a vontade de dormir, que dependem do horário em que o indivíduo acordou ou quando foi dormir. Há uma relação intuitiva entre ambos, de modo que quanto maior o tempo em que está acordado, maior é a vontade para dormir. Por exemplo, se uma pessoa acorda às $5 \mathrm{~h}$, é provável que irá ficar sonolenta por volta das $22 \mathrm{~h}$, pelo fato de estar acordada durante várias horas. O que dissipa a vontade de dormir é o sono. Por outro lado, quanto maior o tempo que a pessoa dorme, mais diminui a vontade para continuar dormindo, levando ao despertar. O Processo C é um ritmo sinosidal que influencia a tendência para o dormir e para o despertar, relacionando-se com o ritmo circadiano que, por sua vez, é dirigido por um mecanismo de relógio no cérebro (KAPLOW, 2005).

Os processos S e C trabalham em tandem. Quando o indivíduo está dormindo, o processo C é lento; quando se encontra acordado, o processo C aumenta. O processo S é maior durante o dia, resultando para a necessidade do sono; concomitantemente, o processo C contrabalança a necessidade para dormir, mantendo o indivíduo despertado. No começo da noite, o processo $\mathrm{C}$ diminui e o processo S aumenta, levando o indivíduo a querer dormir (KAPLOW, 2005).

Os dois tipos de sono são o REM (Rapid Eye Moviment) e o NREM (Non Rapid Eye Moviment). O sono NREM pode ser subdividido em quatro estágios, com características distintas, sendo o estágio 1 o de sono mais leve e o estágio 4 o de 
sono mais profundo. O sono NREM também pode ser chamado de sono quieto, pois a maior parte das atividades fisiológicas está diminuída neste momento; a atividade cognitiva é mínima, mas movimentos periódicos do corpo precedem as mudanças de um estágio para o outro. Contrariamente, o sono REM é também chamado paradóxico, ativo ou rápido, pois é caracterizado por uma ativação eletroencefalográfica, atonia muscular e movimentos oculares rápidos. Com exceção dos músculos posturais e respiratórios, o corpo encontra-se essencialmente paralisado durante o REM (SAVARD; MORIN, 2001).

O sono está bem organizado e estruturado em ciclos NREM-REM, que ocorrem por volta de quatro ou cinco vezes no decorrer da noite. Um adulto normal jovem entra no sono através dos estágios ou fases NREM (Figura 1). O estágio 1 é um breve período transicional entre estar acordado e dormindo, com duração de 5 minutos, sendo portanto um sono muito leve. O estágio 2, que dura cerca de 10 a 20 minutos, durante o ciclo inicial, é considerado o verdadeiro sono fisiológico. Os estágios 3 e 4, também chamados delta ou de ondas lentas, são os mais profundos e podem durar entre 20 e 40 minutos no primeiro ciclo de sono. A seqüência inicial é seguida por um retorno aos estágios 4 , ao 3 e ao 2, seguidos de um episódio REM. O primeiro período REM realiza-se de 70 a 90 minutos após o início do sono e tem normalmente breve duração (5 a 15 minutos). Em geral, os quatro ou cinco episódios REM vão aumentando sua duração durante a noite (SAVARD; MORIN, 2001).

A duração dos ciclos NREM-REM é de aproximadamente 90 minutos, mas pode variar entre 70 e 120 minutos. Os períodos delta são predominantes no primeiro terço da noite, enquanto a proporção de sono REM é maior no último terço da noite (SAVARD; MORIN, 2001). 
As durações dos ciclos NREM-REM dependem da idade: os recém nascidos passam $50 \%$ do sono em REM; as crianças iniciam o sono em REM, enquanto adultos iniciam em NREM; o sono REM estabiliza-se na adolescência em torno de $25 \%$ do total de sono, e na idade avançada cai um pouco. Com a idade, também diminuem os estágios 3 e 4, e essas mudanças passam a ser cada vez mais freqüentes, longos períodos acordados durante a noite passam a ser comuns com o avanço da idade (NAGEL et al., 2003).

Acordado

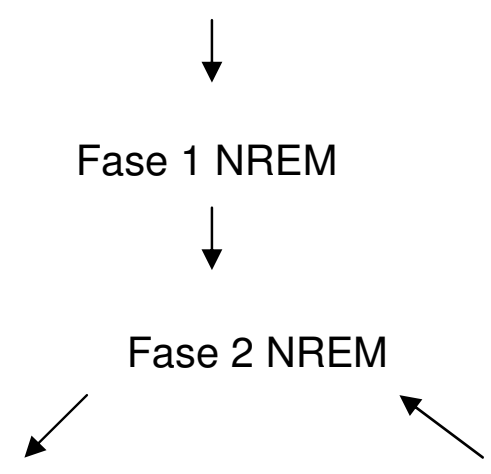

Fase 3 NREM

REM

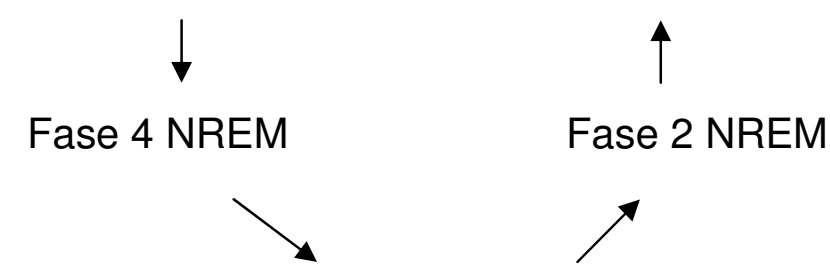

Fase 3 NREM

Figura 1. Seqüência de fases em um ciclo NREM-REM.

Nos pacientes com câncer, todo o mecanismo regulador do sono acima descrito fica alterado. Ainda, os processos S e C são rompidos por uma variedade de razões, podendo ocasionar insônia, dificuldade em iniciar o sono, sonolência, pesadelos, acordar no meio da noite, ficar acordado por um período longo, 
dificuldade em voltar a dormir, acordar muito cedo, cochilar durante o dia (KAPLOW, 2005).

Os distúrbios do sono, que são vivenciados pelos pacientes com câncer, podem ocorrer nos diferentes períodos de atendimento do paciente (tempo de diagnóstico, durante o tratamento, fase terminal). Eles não são problemáticos apenas nestes períodos, mas também podem persistir durante vários meses após o tratamento. Em um estudo, $75 \%$ de pacientes tiveram problemas até o sexto mês, e outro estudo relata distúrbios ocorrendo dois a cinco anos após o tratamento (DAVIDSON et al., 2002).

\subsection{IMPLICAÇÕES DA PRIVAÇÃO DO SONO PARA OS PACIENTES ONCOLÓGICOS}

É sabido que a privação de sono - a insônia - aumenta a fadiga, diminui a tolerância à dor e ocasiona mudança no estado de humor, favorecendo o surgimento de irritabilidade e agressividade. O repouso e o sono são restaurativos; se os mesmos não atingirem níveis adequados ou terapêuticos, a fadiga, que deveria ser aliviada pelo sono, pode tornar-se crônica (ALVAREZ; NAJIB, 2004; ENGSTROM et al., 1999; FERNSEBNER, 1983; LEE, 2001; MACAVOY; MORITZ, 1992; SHEELY, 1996; TRANMER et al., 2003).

Estudos mostram que a fadiga é um sintoma comum durante e após os tratamentos oncológicos. A maior parte dos pacientes submetidos a tratamentos de câncer, como cirurgia, quimioterapia e radioterapia, referiu a fadiga como um fator significante na reabilitação, e muitos sobreviventes oncológicos informaram que ela 
interferiu diretamente na qualidade de vida, em relação ao estado nutricional, nível de atividade diária, anemia, medicamentos, perturbações do sono e fatores psicológicos (ANCOLI-ISRAEL; MOORE; JONES, 2001; ANDERSON et al., 2003; DAWSON et al., 1999; NAIL, 2002; PASSIK et al., 2003).

A percepção de fadiga é influenciada pela qualidade do descanso ou do sono e do quanto este é interrompido pelas variáveis fisiológicas, como apnéia, freqüência urinária, dor, sudorese noturna; ou por variáveis ambientais externas, como barulho ou mudanças nas intensidades de luz. O sono interrompido, qualquer que seja a fonte, resulta em fadiga, independentemente se o indivíduo está a par das interrupções ou de sua causa (LEE, 2001).

Um paciente é considerado com distúrbio do sono depois de quatro noites mal dormidas. Isto faz com que ocorra um aumento dos sintomas que o ocasiona, como dor e ansiedade, diminuindo a habilidade individual de enfrentamento a situações de estresse (FERNSEBNER, 1983).

Estudos apontam que a incidência dos distúrbios do sono nos pacientes com câncer gira em torno de 30 a 50\%, quando comparado aos $15 \%$ na população em geral. Ainda relatam que 23 a $44 \%$ dos pacientes apresentam esse sintoma após dois a cinco anos do tratamento de câncer (VACHANI, 2007).

No estudo de Engstrom et al. (1999), a maioria dos pacientes com distúrbio do sono não comentou sobre o assunto com seu médico. Aqueles que conseguiram identificar um problema físico associado à privação de sono, como dor ou indigestão, procuraram ajuda para resolver estes problemas. Os autores ainda referiram que apenas um paciente atribuiu o problema de não conseguir dormir ao tratamento do câncer; porém, como o tratamento era essencial e nada poderia ser feito para a sua melhora, não comentou com o seu médico. Os participantes desta pesquisa 
identificaram uma variedade de estratégias para lidar com os problemas de sono, como: ler e tomar medicação, meditação, dormir num outro quarto e ir dormir mais tarde. Ainda neste estudo, os pacientes expressaram a preocupação em relação ao impacto de não adquirirem o descanso adequado, principalmente em relação à dificuldade em continuar a desenvolver as atividades diárias a que estavam habituados. Mas, a perturbação do sono foi vista pela maioria dos pacientes como um sintoma que seria temporário e, por isso, não deram a importância devida e não o relacionaram como um sintoma específico.

Muitos autores defendem a idéia de que o distúrbio do sono é uma causa secundária à dor e ao estresse psicológico vivenciado pelos pacientes. No entanto, a verdadeira causa ainda não foi determinada (WEISSMAN; JANJAN; BYHARDT, 1989).

Entre os pacientes hospitalizados, os distúrbios do sono podem ser devidos à ansiedade, depressão, medicações, tratamentos, dor, bem como a fatores relacionados a estes. Além das habilidades físicas estarem prejudicadas, a hospitalização é um período em que os estados de segurança emocional, social e econômica estão ameaçados. Nos pacientes oncológicos, como um fator adicional à hospitalização, há o diagnóstico de doença maligna, que por si só é estressante (LAMB, 1982; SHEELY, 1996). Por outro lado, o estudo de Tanmer et al. (2003) mostrou que quanto maior o tempo de internação hospitalar, melhor é a qualidade de sono, pois os pacientes ficam familiarizados com o ambiente e a rotina, $\mathrm{e}$ conseguem dormir melhor. Ainda no estudo, os idosos relataram uma qualidade pior de sono durante a hospitalização. Isto pode ser pelo fato que os idosos são mais sensíveis ao ambiente externo e aos próprios sentimentos pessoais de dor e ansiedade. Eles também podem ter uma rotina mais pessoal e apresentar maior 
resistência a adaptar-se à nova situação. Embora a qualidade do sono seja uma experiência particular vivenciada por cada indivíduo, os resultados desta pesquisa sugeriram que houve uma semelhança no padrão do sono quanto às condições clínicas, internação hospitalar e idade.

Sabe-se que os pacientes internados no hospital estão mais sujeitos a apresentarem problemas de sono, devido a ruídos, luzes, perturbações noturnas freqüentes, em conjunto com fatores físicos e emocionais, como dor e ansiedade. No entanto, não se sabe qual o impacto, em nível de mensuração, que o ambiente hospitalar pode ocasionar em pacientes que não conseguem o mínimo de sono possível, e até que ponto isto pode ser prejudicial na reabilitação (ANCOLI-ISRAEL; MOORE; JONES, 2001; ENGSTROM et al., 1999; FAULL; HIRSCH, 2000; NAIL, 2002; PASSIK et al., 2003; SHEELY, 1996).

A qualidade de vida, tanto para o paciente como para a família pode ser influenciada pelo distúrbio do sono. Pacientes que acordam durante a noite podem interromper o sono dos membros da família e, se os pacientes e familiares trabalham no período da manhã, o acúmulo de falta de sono pode contribuir para o estresse do sistema familiar (ENGSTROM et al., 1999).

Vale destacar um estudo que mostrou que pacientes oncológicos parecem ter problemas de sono tanto em casa como no hospital, sendo que a queixa principal é a dificuldade em conseguir dormir e a de acordar várias vezes durante a noite, o que é devido a diversos fatores, como exemplo, a dor (ENGSTROM et al., 1999; SHEELY, 1996). 


\subsection{O PAPEL DO ENFERMEIRO NA AVALIAÇÃO E CONTROLE DO SONO DO PACIENTE ONCOLÓGICO}

O cuidado de enfermagem prestado aos sobreviventes do câncer inclui diversas atividades, como a minimização dos efeitos dos tratamentos (fadiga e distúrbio do sono); reconhecimento precoce da recorrência de um novo câncer; avaliação do status psicossocial; implementação de intervenções no que diz respeito ao tratamento da doença; e coordenação da equipe de especialistas e dos cuidadores primários.

Os enfermeiros que cuidam dos pacientes com câncer precisam estar sensibilizados quanto aos distúrbios do sono (ENGSTROM et al., 1999). Detectar pacientes que apresentam problemas de sono representa o primeiro passo para chamar a atenção dos profissionais, que atuam na área da oncologia, para a insônia. Uma vez descoberta a ocorrência, pode-se dar início à investigação de intervenções médicas e não médicas, o que pode ser classificado como uma atenção compreensiva do cuidado, e com isso aumentar potencialmente a satisfação e a qualidade de vida do paciente. Tais intervenções ainda poderiam incluir informações realistas em relação ao problema, planejamento e implementação de modalidades com poder de resolução, como terapia de relaxamento.

As enfermeiras que são responsáveis pelas orientações para a alta hospitalar precisam estar atentas para avaliar as preocupações do paciente e seus familiares. Se a família estiver cansada devido à falta de sono, a habilidade para concentração ou percepção, a fim de entender as informações que serão fornecidas, pode estar diminuída. Materiais escritos e instruções repetidas são essenciais para aumentar a apreensão das informações verbais fornecidas. 
Embora não seja fadiscernir os sintomas relacionados aos problemas físicos e/ou psicológicos, a enfermeira deve reconhecer que o paciente está apresentando privação de sono, devido às suas mudanças de comportamento. Assim, a relação e a comunicação empáticas do enfermeiro com o paciente impõem-se como uma habilidade profissional fundamental.

Como as perturbações de sono e os sintomas altamente estressantes são comuns nos pacientes com câncer, é crucial que seja elaborado um instrumento preciso que detecte a existência desses problemas. Focalizar a insônia faz parte da prática compreensiva de oncologia (PASSIK et al., 2003)

Algumas medidas para minimizar as perturbações do sono, apresentadas na literatura, podem ser listadas como segue:

Durante a internação hospitalar:

a) examinar as rotinas de cuidados que serão administrados aos pacientes, para evitar tarefas dispensáveis durante o período noturno;

b) avaliar o número de pessoas da equipe de saúde que irá oferecer cuidados ao paciente, a fim de evitar que se entre no quarto diversas vezes;

c) coordenar os cuidados que irão ser prestados por outros profissionais da saúde;

d) solicitar que as portas para os quartos dos pacientes possuam janelas, pois assim a observação poderá ser realizada sem precisar entrar no quarto, quando a ocasião não solicitar;

e) usar bombas de infusão endovenosa, pois as mesmas podem ser programadas para administrar fluidos e medicamentos durante períodos prolongados. 
f) Deve-se notar entretanto que, se as condições do paciente requererem, as rotinas hospitalares devem ser avaliadas, a fim de se garantir a segurança do paciente.

Após a alta hospitalar:

a) evitar ingerir alimentos muito calóricos, açucarados e bebidas com cafeína antes de quatro horas do horário para dormir;

b) evitar tirar cochilos muito longos durante o dia;

c) não ingerir bebida alcoólica ou fumar no período de 4 a 6 horas antes do horário de dormir;

d) manter um padrão no horário do sono (NATIONAL..., 2007; TRANMER et al., 2003).

Os progressos tecnológicos dos meios diagnósticos e dos procedimentos terapêuticos têm ampliado a sobrevivência dos pacientes. Embora não tenhamos dados nacionais, no ano de 2006, os EUA divulgaram a existência de mais de 10 milhões de sobreviventes da doença (HEWITT; GREENFIELD; STOVALL, 2006). Neste contexto, surgiu a preocupação com a reabilitação, a sobrevivência e qualidade de vida dos pacientes, com foco na redução das morbidades.

Um número significativo de pacientes tem conseguido sucesso no tratamento do câncer. No mundo inteiro, 54,5 milhões de pessoas receberam o diagnóstico de câncer nos últimos cinco anos e 48\%, ou 24,6 milhões, terão sobrevivido à doença após cinco anos. Porém, é importante ressaltar que ajudar na sobrevivência das pessoas não deve ser algo relacionado apenas a dados estatísticos, pois a qualidade de vida requer avaliação contínua, independente da fase da doença. Desta forma, os profissionais da área da saúde devem estar preparados para identificar os vários distúrbios, como o sono, que os indivíduos 
estejam vivenciando durante a sobrevivência ao câncer, e oferecer opções no tratamento para obter uma melhora na qualidade de vida. Com isso, entendemos que a base para o desenvolvimento deste estudo é uma interação do modelo de sobrevivência com a qualidade de vida.

As conseqüências dos distúrbios do sono são fortemente relacionadas à qualidade de vida. O conceito de qualidade de vida proposto pela Organização Mundial de Saúde engloba domínios da saúde física, relações sociais, grau de independência, características ambientais, variáveis psicológicas e espirituais. A qualidade do sono e a qualidade de vida estão intimamente relacionadas. O desemprego, por exemplo, é fator de qualidade de vida que pode afetar a qualidade do sono de um indivíduo, porque a preocupação presente nessa situação aumenta a latência do sono e os despertares noturnos. Por outro lado, um indivíduo portador de distúrbio do sono provavelmente sofrerá conseqüências no trabalho, devido à má qualidade do sono (MÜLLER; GUIMARÃES, 2007).

O sofrimento clínico da pessoa portadora de distúrbio do sono varia conforme os prejuízos ou conseqüências sofridas e a importância atribuída à área prejudicada. Com isso, vem a importância que a pessoa desenvolva estratégias para manejar essas dificuldades, e melhorar suas condições de vida. Os esforços para compensar os déficits percebidos remetem ao conceito de sobrevivência ao câncer, que envolve a adaptação do organismo a situações adversas, como os sintomas de dor, fadiga e depressão, como exemplos, os quais exigem novas formas de comportamento (MÜLLER; GUIMARÃES, 2007).

Sem levar em conta a etiologia, a insônia, como um distúrbio do sono, pode ter um impacto profundo na morbidez, qualidade de vida e sobrevivência. Quando os pacientes adquirem um sono adequado, a tensão fica reduzida, o nível de cortisol 
diminui, e o sistema imune é reativado. Assim, o tratamento de insônia pode melhorar a qualidade de vida significativamente e ainda auxiliar na regressão da doença (O'DONNELL, 2004).

Em relação aos distúrbios do sono nos pacientes com câncer nas especialidades de cabeça e pescoço e urologia, a literatura é bem escassa e os relatos não apresentam com rigor científico uma forma adequada para melhorar o distúrbio. Porém, nos últimos anos as questões relacionadas com a qualidade de vida têm recebido uma atenção especial por parte de pesquisadores, médicos, enfermeiros e pacientes. A qualidade de vida é uma questão que os pacientes levam em consideração, quando precisam decidir entre os tipos de tratamento. Para o câncer da próstata, por exemplo, de acordo com Cella et al. (2004), a investigação do tratamento do mesmo, quando se leva em conta a qualidade de vida, é uma "faca de dois gumes", na qual as agressões ocasionadas pelo tratamento não envolvem apenas o tempo de sobrevivência, mas também as atividades fisiológicas e o bem estar geral.

Vários domínios (bem estar físico, psicológico, bem estar geral, social, religioso) precisam ser levados em consideração, quando a qualidade de vida dos pacientes com câncer é avaliada. É preciso que os clínicos e/ou pesquisadores utilizem instrumentos que capturem os aspectos multidimensionais, mas sem deixar de levar em conta as diversidades socioeconômicas das pessoas. É importante que a equipe de saúde e o paciente com câncer tenham claro a qualidade de vida provável, antes de se iniciar qualquer tipo de tratamento. A equipe médica deve estar ciente do impacto que o tratamento irá ocasionar nos vários aspectos da vida. Isto irá ajudar a identificar e entender os domínios que freqüentemente são mais 
afetados, a fim que se possam desenvolver intervenções de reabilitação, para impedir o seu declínio (MONGA et al., 2005).

A literatura relacionada ao sono do paciente oncológico é escassa e, no levantamento bibliográfico realizado, não foi encontrada nenhuma pesquisa de âmbito nacional. Frente a esse panorama, destacamos a importância desse estudo que busca contribuir para a atenção dos profissionais de saúde para a questão do sono dos pacientes cirúrgicos oncológicos. 
3 OBJETIVOS 


\subsection{OBJETIVO GERAL}

Avaliar os padrões do sono em pacientes cirúrgicos oncológicos após a alta hospitalar e relacioná-los com as dimensões da qualidade de vida.

\subsection{OBJETIVOS ESPECÍFICOS}

$\checkmark$ Caracterizar a amostra de pacientes cirúrgicos oncológicos.

$\checkmark$ Identificar as diversas perturbações do sono a que estão expostos os pacientes cirúrgicos oncológicos.

$\checkmark$ Verificar a influência do distúrbio do sono na qualidade de vida, em pacientes cirúrgicos oncológicos. 
4 MÉTODO 


\subsection{TIPO DE ESTUDO}

Este estudo consiste numa pesquisa exploratória, com delineamento observacional-transversal. A pesquisa exploratória tem início com a delimitação de um fenômeno de interesse - no caso, a privação do sono em pacientes cirúrgicos oncológicos. Além de observar e descrever o fenômeno, a pesquisa exploratória investiga a sua natureza complexa e outros fatores com os quais ele está relacionado. Pelo delineamento observacional-transversal, os sujeitos da pesquisa são avaliados uma única vez. O delineamento transversal, também denominado seccional, tem como vantagens a rapidez, baixo custo, identificação de caso e detecção de grupos de risco (POLIT; BECK; HUNGLER, 2004).

\subsection{POPULAÇÃO E AMOSTRA}

A população do estudo consistiu de todos os pacientes cirúrgicos oncológicos das especialidades de Cabeça e Pescoço e Urologia, de uma instituição hospitalar, que preenchiam os seguintes critérios de inclusão:

$\checkmark$ Pacientes com diagnóstico de câncer e que foram submetidos a procedimento cirúrgico de cabeça e pescoço e de urologia, no período de um até o sexto mês de pós-operatório; que vieram para retorno ambulatorial no período de outubro 2007 a março de 2008; de ambos os sexos; maiores de 18 anos; que 
puderam se comunicar e que aceitaram participar do estudo por meio de assinatura do termo de consentimento livre e esclarecido.

$\checkmark$ Critérios de exclusão: foram excluídos todos os pacientes que tiveram menos de um mês ou mais de seis meses de pós-operatório; os que foram submetidos a procedimentos cirúrgicos, mas não possuíam o diagnóstico de câncer, e aqueles que não quiseram fazer parte do estudo.

A amostra, de conveniência, teve distribuição aleatória, ou seja, a partir do momento que os clientes chegavam para o retorno no serviço de ambulatório, e desde que estivessem no período pós-operatório citado, os mesmos eram convidados a participar deste estudo. Preencherem os requisitos 46 pacientes.

\subsection{LOCAL E PERÍODO}

Os dados foram coletados no período descrito, na Associação de Combate ao Câncer do Brasil Central, que fica localizada em Uberaba, no estado de Minas Gerais, nos ambulatórios de cirurgia de Cabeça e Pescoço e de Urologia.

$\checkmark$ Ambulatório de Cabeça e Pescoço: os atendimentos ocorrem nas segundas e quintas-feiras das $10 \mathrm{~h} 30 \mathrm{~min}$ a 12h 30min, com uma média de 70 pacientes por mês. A participação dos pacientes desta especialidade correspondeu a $30,4 \%(n=14)$.

$\checkmark$ Ambulatório de Urologia: os retornos ambulatoriais ocorrem nas segundas (7h 30min às $10 \mathrm{~h} 30 \mathrm{~min}$ horas) e quartas-feiras (10h 30min a $12 \mathrm{~h} 30 \mathrm{~min}$ horas), com uma média de atendimento de 200 pacientes por mês. A 
participação dos pacientes desta especialidade correspondeu a 69,6 \% ( $\mathrm{n}=$ 32).

A opção pela especialidade de Cabeça e Pescoço deve-se ao fato de ser um campo de pesquisa desenvolvido pela pesquisadora desde a graduação e ser campo de atuação na docência. Segundo o Brasil (2007), estima-se que no Brasil, em 2008, o câncer de traquéia (brônquio e pulmão) será o $2^{0}$ de maior incidência no sexo masculino e o $4^{\circ}$ no sexo feminino.

A opção pela área de urologia foi devido ao aumento do número de casos de câncer, principalmente o da próstata, $1^{\circ}$ lugar segundo Brasil (2007), e os resultados coletados neste estudo comprovaram isso, pois dos 46 pacientes entrevistados 28 (60,9\%) apresentaram este tipo de câncer.

Além disso, foi levado em consideração o fato que estas especialidades têm uma população significativa de pacientes submetidos a cirurgias oncológicas de médio e grande porte, no citado hospital.

\subsection{PROCEDIMENTOS ÉTICOS}

O estudo foi aprovado pelo Comitê de Ética em Pesquisa, da Universidade Federal do Triângulo Mineiro (Anexo A), e autorizado pelo Diretor Clínico do referido hospital (Apêndice A).

Os aspectos éticos foram baseados na Resolução 196/96 sobre pesquisa envolvendo seres humanos. 
Inicialmente foi solicitada aos pacientes a anuência para participação no estudo. Após os mesmos terem sido esclarecidos sobre o tema, objetivo e finalidade do trabalho, bem como sobre a garantia do anonimato, sigilo e privacidade, foi solicitado, a assinatura do termo de Consentimento Livre e Esclarecido. (Apêndice B).

\subsection{INSTRUMENTOS DE COLETA DE DADOS}

Foi delimitado um período de no mínimo um mês de realização de qualquer tipo de cirurgia oncológica, desde que estivessem dentro das duas grandes especialidades citadas anteriormente, até o sexto mês de pós-operatório.

Para a obtenção dos dados foram utilizados três instrumentos: o instrumento A, o Índice de Qualidade do Sono de Pittsburg - PSQI e o European Organization for Research and Treatment of Câncer Quality of Life Questionnaire "Core" 30 itens (EORTC-QLQ-C30), aplicados durante uma entrevista.

\subsubsection{Instrumento A}

Foi elaborado para se obter as características sociais e clínicas dos sujeitos (idade, sexo, renda mensal, estado civil e vinculo empregatício, local do câncer, tempo de cirurgia, tratamento pré ou pós-cirúrgico) e a identificação de aspectos 
relacionados ao sono (causa e preocupações), não focalizadas nos outros dois instrumentos (Apêndice C).

\subsection{2 Índice de Qualidade de Sono de Pittsburg - PSQI}

Índice de Qualidade de Sono de Pittsburg (PSQI), que passou pelo processo de validação para a cultura brasileira por Ceolim (1999), aborda os aspectos relacionados à questão do sono. Esse instrumento é utilizado na mensuração da qualidade subjetiva do sono e para a ocorrência de seus distúrbios; foi desenvolvido e validado por Buysse et al. (1989), apresentando sensibilidade de $89,6 \%$ e uma especificidade de $86,5 \%$. Foi inicialmente aplicado em três grupos distintos, sendo o primeiro grupo, formado por indivíduos sem complicações com o sono, o segundo, por indivíduos que possuíam problemas para dormir e o terceiro grupo por indivíduos depressivos. Ao ser traduzido para o português, manteve sua alta sensibilidade de $80 \%$. No entanto, uma especificidade ligeiramente menor de 68,8\% (CUNHA, 2006).

O questionário contém dez questões, sendo que as questões de número um, dois, três e quatro são abertas e as questões cinco, seis, sete, oito, nove e dez são semi-abertas. Para todas as dez questões do questionário há um espaço para registro de comentários do entrevistado, se houver necessidade. (Anexo B)

O PSQI é constituído de sete componentes: o primeiro refere-se à qualidade subjetiva do sono, ou seja, à percepção individual a respeito da qualidade do sono; o segundo à latência do sono; o terceiro à duração do sono obtida através da relação entre o número de horas dormidas e o número de horas em permanência no leito, 
não necessariamente dormindo; o quarto, à eficiência habitual do sono; o quinto, aos distúrbios do sono, ou seja, presença de situações que comprometam as horas de sono; o sexto, ao uso de medicações, isto é, se o paciente utilizou ou não medicamentos para dormir; e o sétimo, à sonolência diurna e distúrbios durante o dia, referindo-se à alteração na disposição e entusiasmo para execução das atividades rotineiras, determinada por sonolência diurna (CUNHA, 2006).

Este instrumento vem acompanhado de instruções para pontuação de cada um de seus componentes. A pontuação global é determinada pela soma dos sete componentes, cada componente recebendo uma pontuação estabelecida entre zero e três pontos. A pontuação máxima do instrumento é de 21 pontos. Os escores superiores ao valor de cinco pontos indicam qualidade ruim no padrão do sono. Os valores foram obtidos após testes laboratoriais, provenientes de uma alta especificidade e sensibilidade (BUYSSE et al.1989). (Anexo C).

\subsubsection{European Organization for Research and Treatment of Cancer Quality of Life Questionnaire “Core” 30 itens. (EORTC-QLQ-C30)}

Como o Índice de Qualidade de Sono de Pittsburg (PSQI) não aborda os aspectos com o câncer, foi utilizado também o European Organizarion for Research and Treatment of Câncer (EORTC). (Anexo D)

O EORTC-QLQ-C30 inclui:

a) cinco escalas funcionais: função física, cognitiva, emocional, social e desempenho de papéis;

b) três escalas de sintomas: fadiga, dor, náuseas e vômitos; 
c) uma escala de qualidade de vida e saúde global;

d) seis outros itens que avaliam sintomas comumente relatados por doentes com câncer: dispnéia, falta de apetite-anorexia, insônia, constipação e diarréia; e) escala de avaliação de impacto financeiro do tratamento e da doença.

Os escores das escalas e das medidas dos itens individuais variam de 0 a 100, sendo que um valor alto do escore representa um alto nível de resposta. Ou seja, um alto escore para a escala funcional representa um nível funcional saudável, enquanto que um escore alto para a escala de sintomas/itens representa um alto nível de sintomatologia/problema (KAMEO, 2006).

O princípio para determinar os escores das escalas é o mesmo em todos os casos. A forma de pontuação e os cálculos encontram-se no (Anexo E) (KAMEO, 2006).

Os dados foram coletados pela pesquisadora, nos dias dos retornos ambulatoriais citados, a fim de garantir a homogeneidade e a fidedignidade das informações.

\subsection{ANÁLISE ESTATÍSTICA DOS DADOS}

Para a organização dos dados foi criada uma base de dados no programa Excel®; após, os mesmos foram transportados para o programa SPSS "Statistical Package for the Social Sciences". Este último possibilitou a análise estatística dos dados (NORUSSIS, 1992). 


\subsubsection{Métodos para validação dos instrumentos de Avaliação da Qualidade de Vida}

A consistência interna das escalas do PSQI e do EORTC foi verificada por meio do Coeficiente alfa de Cronbach. Este cálculo é adquirido após uma única aplicação do instrumento de medição, produzindo valores entre 0 e 1 , ou entre 0 e 100\%. Quando maior que 70\% diz-se que há confiabilidade das medidas. São calculadas todas as correlações $(p)$ entre o escore de cada item e o escore total dos demais itens (MARTINS, 2006).

Realizou-se ainda a análise de correlação entre o Estado Geral de Saúde (EGS) do EORTC com o escore Global do PSQI e entre as medidas obtidas do instrumento do escore global do PSQI com o domínio de Insônia do EORTC. Para estudar a associação entre estas variáveis, calculou-se o coeficiente de correlação de Pearson, que é uma medida entre -1 e 1, onde o valor zero indica que as variáveis analisadas não possuem correlação, ou seja, o comportamento de uma variável independe de outra (BARBOSA, 2003).

\subsubsection{Verificação da associação entre as escalas do PSQI com as variáveis sociais e clínicas}

As variáveis dos dados sociais e clínicos são apresentadas após análise estatística descritiva, por meio do cálculo da média, desvio-padrão e análise inferencial, através do procedimento estatístico para o intervalo de confiança de 
95\%, usados para estimar o valor médio real das variáveis quantitativas e porcentagens reais de alguns eventos de interesse do estudo.

Os escores das escalas do PSQI e do EORTC-QLQ-C30 foram submetidos aos seguintes tratamentos estatísticos: intervalo de confiança de 95\%, para estimação dos valores médios das variáveis quantitativas dos eventos de interesse, e teste paramétrico da Análise de Variância (ANOVA).

Para este estudo, adotou-se $\mathrm{P}$ value inferior a 0,05 como estatisticamente significante. 
5 RESULTADOS E DISCUSSÃO 
Os resultados e discussão estão apresentados em três partes: a primeira refere-se à caracterização da amostra segundo as variáveis sociodemográficas e clínicas, as variáveis do EORTC e os resultados do teste de Confiabilidade Alfa de Cronbach e Correlação de Pearson para os instrumentos do PSQI e EORTC, na amostra estudada; a segunda, os resultados do questionário do Índice de Qualidade do Sono de Pittsburgh - PSQI; e a terceira, à relação dos dados sociodemográficos e clínicos e domínio do EORTC e o escore global do PSQI.

\subsection{CARACTERIZAÇÃO DA AMOSTRA E APLICAÇÃO DOS TESTES DE CONFIABILIDADE E CORRELAÇÃO.}

Participaram do estudo 46 pacientes que foram submetidos a procedimento cirúrgico, nas especialidades de Cabeça e Pescoço e de Urologia, por apresentar o diagnóstico de câncer.

A tabela 1 apresenta a caracterização dos participantes, quanto às variáveis sociodemográficas (faixa etária, sexo, renda, escolaridade, estado civil, vínculo empregatício), e clínicas (local do câncer, período pós-operatório, tratamento préoperatório, tratamento pós-operatório). 
Tabela 1 - Caracterização da amostra segundo as variáveis sócio-demográficas e clínicas. Uberaba (MG) - 2008.

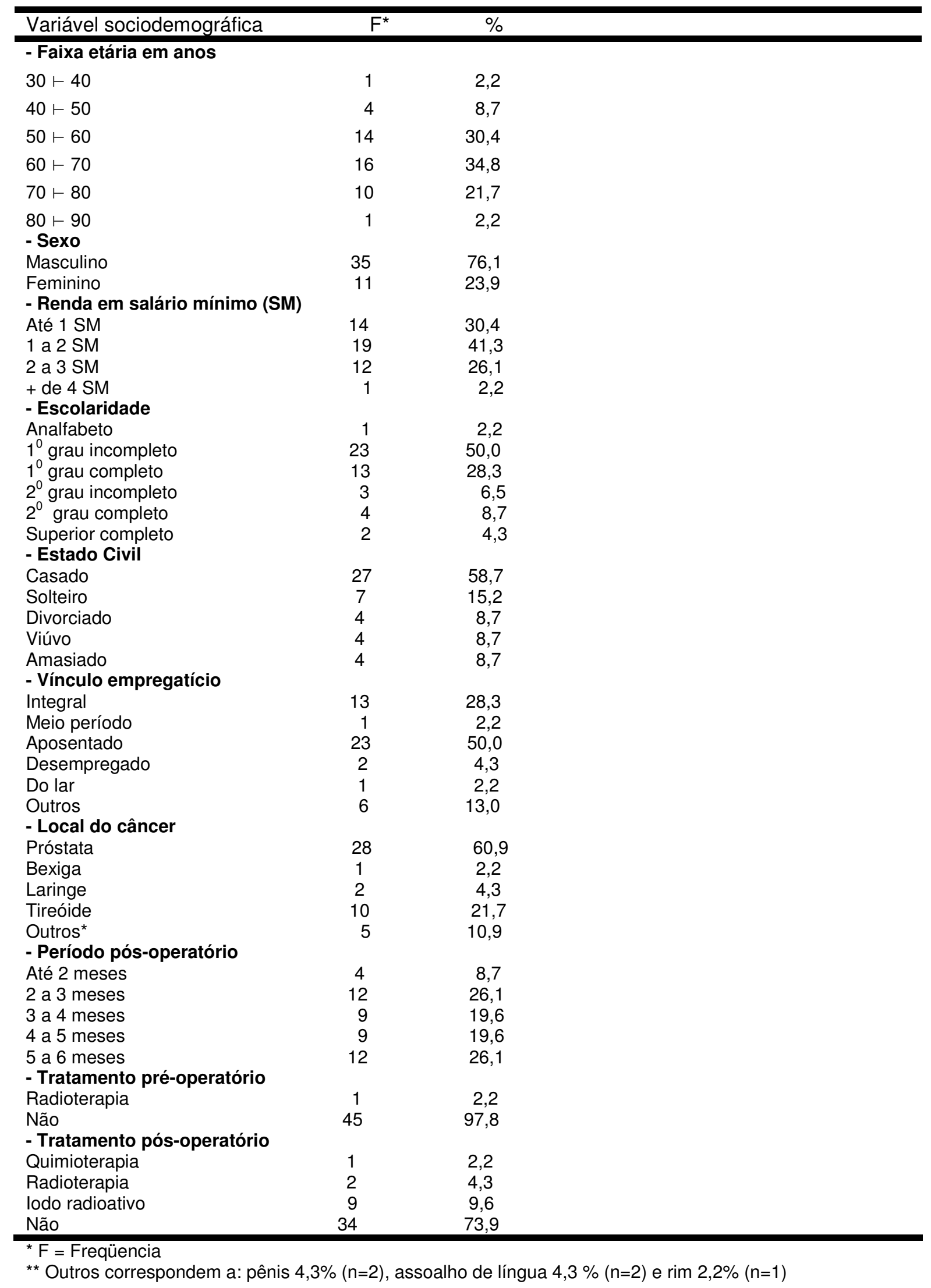


A faixa etária predominante foi a de $60 \vdash 70$, com $34,8 \%$, e o sexo predominante foi o masculino, com $76,1 \%$. O grupo com idade acima dos 50 anos corresponde a $89,1 \%$ dos pacientes, o que está de acordo com a literatura, pois assim como ocorre para outros tipos de câncer, a idade representa um fator de risco importante, uma vez que tanto a incidência, como a mortalidade, aumentam exponencialmente após a idade de 50 anos. (BRASIL, 2007). Porém, em uma revisão bibliográfica realizada por Vena et al. (2004a), alguns estudos que abordavam a faixa etária, dentre os indivíduos com câncer e que relataram distúrbios no padrão do sono mostraram resultados inconsistentes, uma vez que a faixa etária não foi significante.

A renda mensal de 1 a 2 SM $(41,3 \%)$ e a escolaridade com o primeiro grau incompleto $(50,0 \%)$ foram os que apresentaram uma maior porcentagem nos entrevistados. A renda de até dois salários mínimos (com 71,7\%), e a escolaridade até o primeiro grau completo (com $80,5 \%$ ), podem ser indicativos de que os pacientes nessa faixa da amostragem vivem em condições precárias, decorrentes da reduzida qualificação ocupacional e baixa escolaridade de seus integrantes, tendo acesso limitado aos serviços públicos, como educação e saúde (GUIMARÃES; ROMANELLI, 2002). Desta forma não tiveram o conhecimento suficiente quanto aos cuidados para a prevenção ou diagnóstico precoce da doença.

A tabela também aponta que os casados apresentaram freqüência maior $(58,7 \%)$, seguidos pelos solteiros $(15,2 \%)$. Quanto ao vínculo empregatício, 23 pacientes $(50,0 \%)$ eram aposentados e $13(28,3 \%)$ trabalhavam em período integral. Anderson et al. (2003) ressaltaram em sua pesquisa que os pacientes que se encontravam incapacitados, desempregados ou aposentados reportaram uma fadiga 
mais pronunciada que os pacientes que estavam empregados em período integral ou meio-período.

Os pacientes submetidos a procedimentos cirúrgicos na área de Cabeça e Pescoço, observa-se que corresponderam a $30,4 \%$ dos pacientes ( $n=14)$, com 0 câncer ocorrendo na tireóide (10), laringe (2) e assoalho de língua (2), enquanto os da Urologia foram responsáveis por $69,6 \%(n=32)$, com o câncer da próstata $(28)$, pênis (2), bexiga (1) e rim (1). O câncer de próstata, conforme salientado previamente, depois do câncer de pele do tipo não melanoma, deverá ser o mais freqüente na população masculina em 2008, no Brasil. Apenas para o Estado de Minas Gerais e a cidade de Belo Horizonte, o Brasil (2007) estima que ocorra uma incidência de 5.050 novos casos de câncer de próstata.

Os períodos de pós-operatórios mais encontrados foram os de 2 a 3 meses e de 5 a 6 meses, que apresentaram a mesma freqüência de $12(26,1 \%)$ cada um. Com relação aos tratamentos adjuvantes e neo adjuvantes, quase a totalidade dos pacientes (45, isto é $97,8 \%$ ) não foi submetida a nenhum tipo de tratamento no préoperatório, e a grande maioria (34 pacientes ou 73,9\%) não teve também tratamento no pós-operatório.

Embora a freqüência dos pacientes entrevistados submetidos a quimioterapia e radioterapia ter sido pequena, não podemos deixar de mencionar a importância dessas terapêuticas com referência à qualidade do sono. Graci (2005) referiu em seu estudo que tanto a quimioterapia como a radioterapia estão associadas com disfunção do sono e sonolência diurna, podendo levar o indivíduo a apresentar fadiga mais acentuada. Esta idéia é sustentada pelas normas e recomendações do Normas... (2000), onde salienta-se que tanto a quimioterapia (1-2 semanas após), 
como a radioterapia (no final da aplicação) podem provocar cansaço extremo, com duração de até três semanas.

Vena et al. (2004b) relatam ainda que medidas objetivas do sono, bem como descrições clínicas detalhadas, são muito limitadas em pacientes submetidos a quimioterapia. Portanto, os efeitos diretos ou indiretos dos agentes quimioterápicos, relativos aos distúrbios do sono, ainda são desconhecidos.

Embora haja uma pequena produção científica sobre os efeitos da radioterapia no sono, alguns pesquisadores acreditam que alterações das citosinas podem ser um fator importante. Pois, o nível sérico de IL-1 aumentou, durante as primeiras quatro semanas de tratamento, nos pacientes que estavam sendo submetidos a radioterapia e, pelo menos para alguns pacientes, o número de horas dormidas e o nível sérico de IL-1 estavam significativamente correlacionados (VENA et al., 2004b).

A cirurgia de tireoidectomia, total ou parcial, quando comprovada a malignidade pelo exame anátomo-patológico, é geralmente seguida de tratamento com iodo radiativo, para destruir tanto os resíduos de células tireoideanas normais, como de células cancerosas. (BRASIL, 2007).

As respostas aos itens 7 e 8 do instrumento $A$ (referentes à Tabela 1) não foram tabuladas por não terem sido consideradas significantes para este estudo.

A tabela 2 apresenta todas as freqüências e porcentagens dos 46 pacientes entrevistados, em relação aos quinze domínios do EORTC. No anexo E, encontramse todos os detalhes para cálculo e significado dos escores. 
Tabela 2 - Caracterização da amostra segundo os domínios e os escores do EORTC. Uberaba (MG) - 2008.

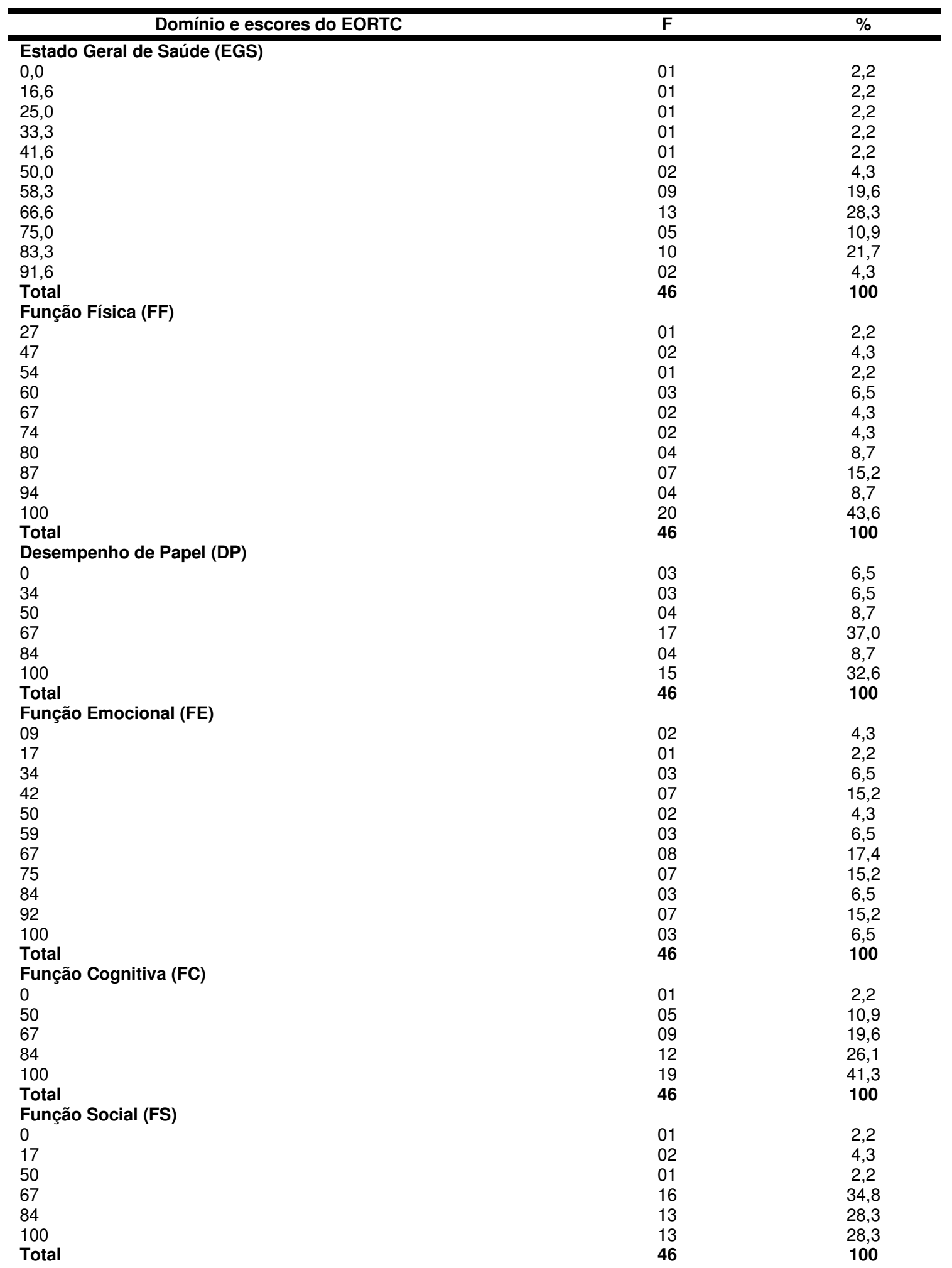




\begin{tabular}{|c|c|c|}
\hline . & $\mathbf{F}$ & $\%$ \\
\hline \multicolumn{3}{|c|}{ Fadiga (FAD) } \\
\hline 0,0 & 04 & 8,7 \\
\hline 11,1 & 05 & 10,9 \\
\hline 22,2 & 13 & 28,3 \\
\hline 33,3 & 16 & 34,8 \\
\hline 44,4 & 03 & 6,5 \\
\hline 55,5 & 02 & 4,3 \\
\hline 66,6 & 01 & 2,2 \\
\hline 77,7 & 01 & 2,2 \\
\hline 88,8 & 01 & 2,2 \\
\hline Total & 46 & 100 \\
\hline \multicolumn{3}{|c|}{ Náuseas e vômitos (NAV) } \\
\hline 0,0 & 40 & 87,0 \\
\hline 16,6 & 03 & 6,5 \\
\hline 33,3 & 01 & 2,2 \\
\hline 100 & 02 & 4,3 \\
\hline Total & 46 & 100 \\
\hline \multicolumn{3}{|l|}{ Dor } \\
\hline 0,0 & 14 & 30,4 \\
\hline 16,6 & 09 & 19,6 \\
\hline 33,3 & 07 & 15,2 \\
\hline 50,0 & 04 & 8,7 \\
\hline 66,6 & 07 & 15,2 \\
\hline 83,3 & 01 & 2,2 \\
\hline 100 & 04 & 8,7 \\
\hline Total & 46 & 100 \\
\hline \multicolumn{3}{|c|}{ Dispnéia (DIS) } \\
\hline 0,0 & 38 & 82,6 \\
\hline 33,0 & 03 & 6,5 \\
\hline 66,0 & 02 & 4,3 \\
\hline 100 & 03 & 6,5 \\
\hline Total & 46 & 100 \\
\hline \multicolumn{3}{|c|}{ Insônia (INS) } \\
\hline 0,0 & 13 & 28,3 \\
\hline 33,0 & 12 & 26,1 \\
\hline 66,0 & 11 & 23,9 \\
\hline 100,0 & 10 & 21,7 \\
\hline \multirow{2}{*}{\multicolumn{3}{|c|}{ Perda de Apetite (PAP) }} \\
\hline & & \\
\hline 0,0 & 43 & 93,5 \\
\hline 1,0 & 01 & 2,2 \\
\hline 33,3 & 02 & 4,3 \\
\hline Total & 46 & 100 \\
\hline \multicolumn{3}{|c|}{ Constipação (CON) } \\
\hline 0,0 & 42 & 91,3 \\
\hline 1,0 & 01 & 2,2 \\
\hline 33,0 & 01 & 2,2 \\
\hline 100 & 02 & 4,3 \\
\hline Total & 46 & 100 \\
\hline \multicolumn{3}{|c|}{ Diarréia (DIA) } \\
\hline 0,0 & 45 & 97,8 \\
\hline 1,0 & 01 & 2,2 \\
\hline Total & 46 & 100 \\
\hline \multicolumn{3}{|c|}{ Dificuldades Financeiras (DIF) } \\
\hline 0,0 & 23 & 50,0 \\
\hline 1,0 & 01 & 2,2 \\
\hline 33,0 & 17 & 37,0 \\
\hline 66,0 & 02 & 4,3 \\
\hline 100 & 03 & 6,5 \\
\hline Total & 46 & 100 \\
\hline
\end{tabular}

Com o conhecimento adquirido para interpretar a tabela 2, percebe-se que mais da metade dos pacientes, isto é $63,2 \%$ (ou 29 pacientes) apresentou um EGS não superior a $66,6 \%$, caracterizando limitação da qualidade de vida. 
Para as escalas funcionais, ressalta-se limitação para nível de escore não superior a $67 \%$ tanto para o desempenho de papel (27 pacientes ou $58,7 \%$ ), como para a função emocional (26 pacientes ou 56,4\%), revelando comprometimento destas atividades.

Segundo Burke (2006), os fatores internos (psicológico e fisiológico) e os externos relacionados ao distúrbio do sono estão apenas no início de sua investigação. Pois, a literatura científica ainda não traz com propriedade os resultados e as conseqüências do distúrbio do sono, como irritabilidade, falta de concentração, dificuldade para a tomada de decisões, bem como os efeitos sobre a qualidade de vida dos sobreviventes ao câncer, no seu modo de viver, incluindo família, trabalho e vida social.

A fadiga, em nível de escore superior a $22,2 \%$, ocorreu em mais da metade dos pacientes, isto é $52,2 \%$ ou 24 pacientes. Isto revela a presença deste sintoma como um fator importante entre os entrevistados.

A fadiga é um dos sintomas mais relatados entre os pacientes com câncer, sendo responsável por um maior nível de estresse e resultando de uma forma negativa na vida diária do paciente. As causas da fadiga podem ser devidas a vários fatores, como o diagnóstico da doença, o tratamento, as medicações e distúrbios do sono. A fadiga relacionada ao câncer é um problema clínico com uma abordagem complexa, multifatorial e multidimensional. Atualmente não existe um método padrão para mensurar a fadiga relacionada ao câncer, o que torna difícil determinar a forma de comparabilidade dos resultados já encontrados nas pesquisas (BURKE, 2006).

Mota (2008), ao validar para a língua portuguesa brasileira o instrumento multidimensional Escala de Fadiga de Piper - Revisada, para diagnosticar a prevalência da fadiga em pacientes com câncer colo-retal, observou que o sintoma 
estava presente em $26,8 \%$ dos entrevistados. Porém, a própria autora referiu algumas limitações no seu estudo, como: a amostra não aleatória, impedindo generalizações; a variável sobre o tratamento do câncer indagava apenas se o indivíduo havia realizado quimioterapia ou radioterapia, o que pode ter mascarado alguma diferença; não foram investigadas alterações do funcionamento do tubo gastrintestinal, como diarréia e constipação.

A insônia afetou 21 pacientes (45,6\%), em um nível superior a 33\%. A insônia pode ser definida como a dificuldade em iniciar ou manter o sono, ou sendo um sono que não é considerado restaurativo, levando a um estado clínico significante de estresse, com alterações no convívio social, profissional e familiar (BECK; DUDLEY; BARSEVICK, 2005).

Segundo Graci (2005), os problemas mais comuns para o distúrbio do sono são a insônia e as desordens das vias aéreas, como a dispnéia e apnéia. A autora afirma ainda que o critério geral estabelecido pelas pesquisas para afirmar que o indivíduo está com insônia é ele apresentar dificuldade em iniciar o sono, em permanecer dormindo e despertar muito cedo.

Uma forma de avaliar se a qualidade do sono é adequada consiste em determinar o padrão do sono do paciente. Para tal, os profissionais da área de saúde devem investigar a rotina dos pacientes, a fim de determinar o horário que vão dormir, o tempo que levam para adormecer, a duração do sono, o número de vezes que acordam no meio da noite, quanto tempo levam para voltar a dormir e o horário de levantar. Estes dados vão ajudar a determinar o padrão do sono dos pacientes e perceber se houve alguma mudança após o diagnóstico de câncer e/ou tratamento (O'DONNELL, 2004). 
A dor esteve presente, em intensidade superior a $16,6 \%$, em metade dos pacientes e dificuldade financeira, igual ou superior a $33 \%$, ocorreu em quase metade dos pacientes (47,8\% ou 22 pacientes). Beck, Dudley e Barsevick (2005) referiram que a dor é vivenciada tanto pelos pacientes com câncer que estão recebendo tratamento oncológico, como por aqueles que se encontram em fase avançada da doença. Aproximadamente 33 a 50\% dos sobreviventes do câncer referiram ter sentido dor em algum momento da doença.

Na tabela 3, com o intuito de avaliar a consistência dos instrumentos do PSQI e do EORTC, foi aplicado o Teste Alfa de Cronbach, que trabalha com a covariância e variâncias internas das medidas. Os valores deste teste variam de 0 a 1 e quanto maior o coeficiente, maior a consistência interna e homogeneidade dos itens, indicando a acurácia da medida.

Tabela 3 - Confiabilidade Alfa de Cronbach da escala do PSQI e do EORTC, na amostra de pacientes cirúrgicos oncológicos. Uberaba (MG) - 2008.

\begin{tabular}{lcccc}
\multicolumn{1}{c}{ Escala } & $\mathbf{N}^{\mathbf{0}}$ itens & $\boldsymbol{\alpha}$ de Cronbach & Mediana & Desvio padrão \\
\hline PSQI & 25 & 0,7940 & 56,0444 & 13,7460 \\
EORTC & 30 & 0,8139 & 56,0435 & 9,6631 \\
\hline
\end{tabular}

Verifica-se que ambos os instrumentos utilizados apresentaram Alfa de Cronbach superior a 0,70 indicando elevada consistência interna e homogeneidade dos itens, sendo o PSQI de 0,794 e o EORTC de 0,8139 (MARTINS, 2006).

A Correlação de Pearson, apresentada na tabela 4, é utilizada para avaliação de correlações entre variáveis numéricas contínuas. Para cada paciente, foi anotado o valor do EGS (variável y) e o do PSQI - global (variável x), sendo então realizado o 
teste de correlação, avaliando este conjunto (x,y) nos 46 pacientes da amostra. Análise similar foi utilizada para a tabela 5, referente à insônia.

Tabela 4 - Correlação de Pearson entre o Estado Geral de Saúde (EGS) do EORTC e o Escore Global do PSQI, na amostra de pacientes cirúrgicos oncológicos. Uberaba (MG) - 2008.

\begin{tabular}{lcc}
\hline \multicolumn{1}{c}{ Medidas } & PSQI (global) & EGS \\
\hline PSQI (global) & 1,000 & $-0,339^{*}$ \\
EGS & $-0,339^{*}$ & 1,000 \\
\hline
\end{tabular}

${ }^{*} \mathrm{p}<0,05$

O valor negativo dessa correlação demonstra que os instrumentos são medidos de forma inversa, ou seja, quanto maior o escore do EORTC, melhor é a condição física e qualidade de vida, ao contrário do PSQI que quanto maior o escore, pior é a qualidade do sono. Portanto, esse resultado demonstra que os dois instrumentos se correlacionaram inversamente, pois se espera que para ter uma boa qualidade de vida é necessário ter qualidade no padrão de sono.

Tabela 5 - Correlação de Pearson entre as medidas obtidas do instrumento do Escore Global do PSQI com o domínio de Insônia do EORTC. Uberaba (MG) - 2008.

\begin{tabular}{lcc}
\multicolumn{1}{c}{ Medidas } & PSQI (global) & Insônia \\
\hline PSQI (global) & - & $0,710^{*}$ \\
Insônia & $0,710^{*}$ & - \\
\hline${ }^{*} \mathrm{p}<0,01$ & &
\end{tabular}

${ }^{*} p<0,01$

Ao analisar a tabela, percebe-se que o valor de correlação $r=0,710$ indica uma alta correlação positiva entre o escore global do PSQI com o domínio de insônia do EORTC, uma vez que este valor encontra-se perto da medida de valor 1. Este resultado demonstra a validade convergente destes instrumentos. 


\subsection{CARACTERIZAÇÃO DO ÍNDICE DE QUALIDADE DO SONO DE PITTSBURGH $-\mathrm{PSQ}$}

A tabela 6 apresenta as respostas das primeiras quatro perguntas abertas do questionário PSQI e as tabelas 7 e 8 às questões de cinco a dez, que são semiabertas, sendo ambas tabelas relacionadas à frequência e porcentagem.

Tabela 6 - Freqüência e porcentagem das respostas dos sujeitos nas questões abertas do PSQI. Uberaba (MG) - 2008.

\begin{tabular}{llll}
\hline \multicolumn{1}{c}{ Questões } & Respostas & $\mathbf{F}$ & \% \\
\hline 1- A que horas foi deitar & $19 \vdash 21 \mathrm{~h}$ & 7 & 15,2 \\
& $21 \vdash 23 \mathrm{~h}$ & 37 & 80,4 \\
& $23 \vdash 1 \mathrm{~h}$ & 1 & 2,2 \\
& $1 \vdash 3 \mathrm{~h}$ & 0 & 0 \\
& $3 \vdash 5 \mathrm{~h}$ & 1 & 2,2 \\
2- Quanto tempo (em minutos) demorou para & $<\mathrm{ou}=15 \mathrm{~min}$ & 17 & 37,0 \\
pegar no sono & $16-30 \mathrm{~min}$ & 15 & 32,6 \\
& $31-60 \mathrm{~min}$ & 08 & 17,4 \\
3- A que horas acordou de manhã & $>60 \mathrm{~min}$ & 06 & 13,0 \\
& $3 \vdash 4 \mathrm{~h}$ & 01 & 2,2 \\
& $4 \vdash 5 \mathrm{~h}$ & 02 & 4,3 \\
& $5 \vdash 6 \mathrm{~h}$ & 13 & 28,3 \\
& $6 \vdash 7 \mathrm{~h}$ & 25 & 54,3 \\
& $>7 \mathrm{~h}$ & 05 & 10,9 \\
4- Quantas horas de sono por noite dormiu & $1 \vdash 2 \mathrm{~h}$ & 01 & 2,2 \\
& $2 \vdash 3 \mathrm{~h}$ & 02 & 4,3 \\
& $3 \vdash 4 \mathrm{~h}$ & 07 & 15,2 \\
& $4 \vdash 5 \mathrm{~h}$ & 09 & 19,6 \\
& $5 \vdash 6 \mathrm{~h}$ & 05 & 10,9 \\
& $6 \vdash 7 \mathrm{~h}$ & 12 & 26,1 \\
& $7 \vdash 8 \mathrm{~h}$ & 05 & 10,9 \\
& $8 \vdash 9 \mathrm{~h}$ & 03 & 6,5 \\
& $9 \vdash 10 \mathrm{~h}$ & 02 & 4,3 \\
\hline
\end{tabular}

Verifica-se que a maior freqüência do horário para se deitar ocorreu entre 21 a 23 horas (80,4\%), levar até 15 minutos para pegar no sono (37\%), acordar entre 6 e 7 horas $(54,3 \%)$ e dormir por noite uma média de 6 a 7 horas $(26,1 \%)$. 
No estudo de Mercadante, Girelli e Casuccio (2004), onde foram entrevistados 123 pacientes, os autores obtiveram uma média de duração do sono (horas dormidas) de 6,58 horas; 37 pacientes (30\%) dormiram menos de 5 horas e $86(70 \%)$ dormiram mais de 5 horas por noite. Entretanto, ainda não há na literatura um consenso de quantas horas dormidas seja o ideal, pois não existem instrumentos para mensurar o quantitativo do sono, considerando as diversas variáveis intervenientes.

Tabela 7 - Freqüência e porcentagem das respostas dos sujeitos nas questões semiabertas do PSQI. Uberaba (MG) - 2008.

\begin{tabular}{|c|c|c|c|c|c|c|c|c|c|c|}
\hline \multirow[t]{2}{*}{ QUESTÓES } & \multicolumn{2}{|c|}{1} & \multicolumn{2}{|c|}{2} & \multicolumn{2}{|c|}{3} & \multicolumn{2}{|c|}{4} & \multicolumn{2}{|c|}{ TOTAL } \\
\hline & $\mathrm{F}$ & $\%$ & $\mathrm{~F}$ & $\%$ & $\mathrm{~F}$ & $\%$ & $\mathrm{~F}$ & $\%$ & $\mathrm{~F}$ & $\%$ \\
\hline $\begin{array}{l}\text { 5a) Demorar mais de trinta } \\
\text { minutos para pegar no sono }\end{array}$ & 16 & 34,7 & - & - & 11 & 23,9 & 19 & 41,3 & 46 & 100 \\
\hline $\begin{array}{l}\text { 5b) Acordar no meio da noite } \\
\text { ou de manhã muito cedo }\end{array}$ & 6 & 13,0 & 1 & 2,2 & 7 & 15,2 & 32 & 69,5 & 46 & 100 \\
\hline $\begin{array}{l}\text { 5c) Levantar-se para ir ao } \\
\text { banheiro }\end{array}$ & 3 & 6,5 & 5 & 10,9 & 5 & 10,9 & 33 & 71,7 & 46 & 100 \\
\hline $\begin{array}{l}\text { 5d) Ter dificuldade para } \\
\text { respirar }\end{array}$ & 38 & 82,6 & - & - & 3 & 6,5 & 5 & 10,9 & 46 & 100 \\
\hline 5e) Tossir ou roncar muito alto & 41 & 89,1 & 1 & 2,2 & 1 & 2,2 & 3 & 6,5 & 46 & 100 \\
\hline 5f) Sentir muito frio & 44 & 95,6 & 1 & 2,2 & - & - & 1 & 2,2 & 46 & 100 \\
\hline $5 \mathrm{~g})$ Sentir muito calor & 36 & 78,3 & 2 & 4,3 & 3 & 6,5 & 5 & 10,9 & 46 & 100 \\
\hline $\begin{array}{l}\text { 5h) Ter sonhos ruins ou } \\
\text { pesadelos }\end{array}$ & 34 & 73,9 & 4 & 8,7 & 4 & 8,7 & 4 & 8,7 & 46 & 100 \\
\hline 6- Qualidade do sono & 9 & 19,6 & 18 & 39,1 & 14 & 30,4 & 5 & 10,9 & 46 & 100 \\
\hline $\begin{array}{l}\text { 7- Tomar algum remédio para } \\
\text { dormir }\end{array}$ & 39 & 84,7 & 1 & 2,2 & 1 & 2,2 & 5 & 10,9 & 46 & 100 \\
\hline $\begin{array}{l}\text { 8- Dificuldade de ficar acordado } \\
\text { enquanto estava dirigindo... }\end{array}$ & 23 & 50,0 & 4 & 8,7 & 16 & 34,8 & 3 & 6,5 & 46 & 100 \\
\hline $\begin{array}{l}\text { 9- Sentir indisposição ou falta } \\
\text { de entusiasmo }\end{array}$ & 17 & 36,9 & 19 & 41,3 & 4 & 8,7 & 6 & 13,0 & 46 & 100 \\
\hline
\end{tabular}


Dentre os resultados da tabela, salientam-se alguns itens que chamam a atenção, como os 19 pacientes $(41,3 \%)$ que levam mais de trinta minutos para dormir, os 32 pacientes $(69,5 \%)$ que acordam no meio da noite ou muito cedo, e os $33(71,7 \%)$ que levantam para ir ao banheiro.

Existem diversas pesquisas que tratam o distúrbio do sono entre pacientes com câncer, relacionando-o às questões apresentadas na tabela anterior. Os principais resultados são colocados a seguir.

Engstrom et al. (1999) relataram em sua pesquisa que problemas que levavam ao distúrbio do sono eram vivenciados freqüentemente pelos pacientes. Quase a metade dos entrevistados (45\%) referiu problemas para dormir todas as noites e $25 \%$ de três a quatro vezes por semana. O problema mais comum foi o de acordar durante a noite e demorar mais de trinta minutos para voltar a dormir, seguido pela queixa de conseguir dormir menos horas por noite do que o normal.

No estudo de Furlani e Ceolim (2006), entre os sujeitos com má qualidade de sono, destacaram-se como problemas o despertar precoce $(92 \%)$ e a necessidade de ir ao banheiro (92\%), seguidos pelos episódios de dor $(69,3 \%)$ e pela sensação de calor durante a noite $(46,2 \%)$.

Simeit, Deck e Marx (2004) trouxeram como resultados, para distúrbios do sono caracterizados pelos pacientes, as ocorrências de acordar diversas vezes durante a noite (76 a 90\%), dormir menos horas que o normal (84 a $85 \%$ ), dificuldade em voltar a dormir (35 a 75\%), dificuldade em iniciar o sono (44\%) e cansaço durante o dia (37\%). Sobre estas cinco ocorrências, uma pesquisa desenvolvida por Davidson et al. (2002) revelou que 59\% de seus pacientes apresentaram uma combinação de duas delas; 17\% relataram uma combinação de três das mesmas; e 7\%, uma combinação de quatro delas. 
Davidson et al. (2002) informaram ainda que quando o distúrbio do sono já existia antes do paciente ter o conhecimento do diagnóstico de câncer, os sintomas eram agravados em $58 \%$ dos pacientes após receber o diagnóstico. Este achado vem de encontro ao relato de Sela, Watanabe e Nekolaichuk (2005), em que 72\% dos participantes informaram ter iniciado os distúrbios do sono depois que receberam o diagnóstico de câncer, em relação a 19\% dos participantes que indicaram existência de dificuldade para dormir antes do diagnóstico.

Os distúrbios no padrão do sono indicam um nível no qual o sono está sendo prejudicado por fatores ambientais e/ou pessoais. O índice de prevalência e suas diferenças, para os distúrbios do sono nos pacientes com câncer, podem estar relacionados ao tipo de câncer e ao seu estágio (BECK; DUDLEY; BARSEVICK, 2005). Deve-se notar que em oncologia os estudos dos múltiplos sintomas são complicados, devido às diferenças na origem da doença com os sintomas específicos. Alguns sintomas estão relacionados com a doença, enquanto outros estão relacionados com o tratamento (exemplo: náusea e vômito podem ser resultado de uma obstrução intestinal ou de quimioterapia); ou os sintomas podem estar relacionados com a doença e o tratamento (a fadiga, como exemplo); e ainda há a possibilidade de um ou mais sintomas desencadearem a ocorrência de outro (distúrbio do sono, que pode levar a fadiga) (BECK; DUDLEY; BARSEVICK, 2005).

Quando o padrão do sono foi comparado entre pacientes com câncer e pacientes que não tinham diagnóstico de câncer, os resultados indicaram que aqueles que possuíam o diagnóstico permaneciam mais tempo na cama, porém menos tempo dormindo. Além disso, permaneciam também um tempo maior no estágio I do ciclo do sono (transição entre estar acordado e adormecido), e 
acordavam quase três vezes mais nas fases 3 e 4 (sono profundo) que os que apresentavam um ciclo normal do sono (SILBERFARB, 1988).

Recente estudo sugere que o sono na fase REM é o momento em que novos traços de memória são colocados no cérebro. Assim, uma fase REM diminuída e reduções nas fases 3 e 4 do ciclo do sono podem contribuir para as dificuldades cognitivas experimentadas pelos pacientes com câncer (OLSON et al., 2008).

Na tabela 8, são apresentados resultados referentes à questão número 10 do PSQI, que diz respeito ao significado do sono e aos hábitos de cochilar ou não. As respostas para essas questões não são somadas, ou seja, não são computadas em nenhum dos sete componentes, portanto não entram no escore global do PSQI. No entanto, as respostas dos pacientes que possuem o hábito de cochilar ajudam a compreender a qualidade subjetiva do sono.

Tabela 8 - Freqüência e porcentagem das respostas dos sujeitos na questão de número 10 do PSQI. Uberaba (MG) - 2008.

\begin{tabular}{lcc}
\hline Para você o sono é & $\mathbf{N}$ & $\%$ \\
\hline Prazer & 5 & 10,9 \\
Necessidade & 41 & 89,1 \\
Total & $\mathbf{4 6}$ & $\mathbf{1 0 0}$ \\
- Você cochila & $\mathbf{N}$ & $\%$ \\
Sim & 34 & 73,9 \\
Não & 12 & 26,1 \\
Total & $\mathbf{4 6}$ & $\mathbf{1 0 0}$ \\
& & \\
- Caso sim - Cochila intencionalmente & $\mathbf{N}$ & $\%$ \\
Sim & 34 & 100 \\
Não & - & - \\
Total & $\mathbf{3 4}$ & $\mathbf{1 0 0}$ \\
& & \\
- Para você cochilar é & $\mathbf{N}$ & $\%$ \\
Prazer & 21 & 45,6 \\
Necessidade & 13 & 28,3 \\
Total & $\mathbf{3 4}$ & $\mathbf{1 0 0}$ \\
\hline
\end{tabular}


Conforme os dados na tabela, 41 pacientes $(89,1 \%)$ consideram o sono como sendo uma necessidade. Dos 46 entrevistados, $34(73,9 \%)$ referiram cochilar durante o dia e todos eles o fazem intencionalmente. Observa-se ainda que 21 pacientes $(45,6 \%)$ consideram o ato de cochilar um prazer e $13(28,3 \%)$ como sendo necessidade.

Em dois estudos, Engstrom et al. (1999) e Davidson et al. (2002), foi informado respectivamente que $39 \%$ dos seus respondentes dormiam fora dos horários de costume, como cochilos na parte da manhã e no período da tarde, e $60 \%$ cochilavam durante o dia, pelo menos 3 vezes por semana.

A próxima tabela traz a freqüência e a porcentagem em relação aos sete componentes do PSQI. Como já foi mencionado, este questionário possui sete componentes, sendo eles: 1- qualidade subjetiva do sono; 2 - latência do sono; 3duração do sono; 4- eficiência habitual do sono; 5- distúrbios do sono; 6- uso de medicação para dormir; 7- sonolência diurna e distúrbios durante o dia. Com a somatória dos resultados dos sete componentes, encontrou-se um escore global do PSQI. No anexo C, encontram-se todos os detalhes para este cálculo. 
Tabela 9 - Freqüência e porcentagem das respostas dos sujeitos em relação aos componentes do PSQI. Uberaba - (MG) - 2008.

\begin{tabular}{|c|c|c|}
\hline Componentes e os escores PSQI & $\mathbf{F}$ & $\%$ \\
\hline \multicolumn{3}{|l|}{ Componente 1} \\
\hline 0 & 08 & 17,4 \\
\hline 1 & 18 & 39,1 \\
\hline 2 & 14 & 30,4 \\
\hline 3 & 06 & 13,0 \\
\hline \multirow{2}{*}{\multicolumn{3}{|c|}{ Componente 2}} \\
\hline & & \\
\hline 0 & 13 & 28,3 \\
\hline 1 & 06 & 13,0 \\
\hline 2 & 13 & 28,3 \\
\hline 3 & 14 & 30,4 \\
\hline \multirow{2}{*}{\multicolumn{3}{|c|}{$\begin{array}{l}\text { Componente } 3 \\
\text { Colal }\end{array}$}} \\
\hline & & \\
\hline 0 & 06 & 13,0 \\
\hline 1 & 17 & 37,0 \\
\hline 2 & 06 & 13,0 \\
\hline 3 & 17 & 37,0 \\
\hline \multirow{2}{*}{\multicolumn{3}{|c|}{ Componente 4}} \\
\hline & & \\
\hline 0 & 15 & 32,6 \\
\hline 1 & 04 & 8,7 \\
\hline 2 & 09 & 19,6 \\
\hline 3 & 18 & 39,1 \\
\hline Total & 46 & 100 \\
\hline \multicolumn{3}{|l|}{ Componente 5} \\
\hline 0 & 01 & 2,2 \\
\hline 1 & 39 & 84,8 \\
\hline 2 & 06 & 13,0 \\
\hline \multirow{2}{*}{\multicolumn{3}{|c|}{ Componente 6}} \\
\hline & & \\
\hline 0 & 39 & 84,8 \\
\hline 1 & 01 & 2,2 \\
\hline 2 & 01 & 2,2 \\
\hline 3 & 05 & 10,9 \\
\hline \multirow{2}{*}{\multicolumn{3}{|c|}{ Componente 7}} \\
\hline & & \\
\hline 0 & 13 & 28,3 \\
\hline 1 & 15 & 32,6 \\
\hline 2 & 14 & 30,4 \\
\hline 3 & 04 & 8,7 \\
\hline \multirow{2}{*}{\multicolumn{3}{|c|}{$\begin{array}{l}\text { Total } \\
\text { Escore Global }\end{array}$}} \\
\hline & & \\
\hline 0 a 5 & 12 & 26,1 \\
\hline 6 a 10 & 15 & 32,6 \\
\hline 11 a 15 & 17 & 37,0 \\
\hline 16 a 21 & 02 & 4,3 \\
\hline Total & 46 & 100 \\
\hline
\end{tabular}

Com os resultados descritos na tabela anterior, percebemos que a nossa amostragem possui um comprometimento em todos os componentes, com exceção do componente cinco.

Engstrom et al. (1999) referiram no seu estudo que, apesar dos distúrbios do sono comprometerem a qualidade de vida dos pacientes com câncer, as suas causas não são investigadas e conseqüentemente não são tratadas. Relataram 
ainda que isso é devido, em parte, ao fato que os profissionais não questionam sobre o sono e também que os próprios pacientes não referem os distúrbios aos cuidadores. As questões semi-abertas do PSQI revelaram que: a) muitos pacientes acreditavam que não havia muita coisa que os profissionais poderiam fazer para melhorar a qualidade do sono; b) alguns se mostraram relutantes em fazer uso de medicações sedativas; c) outros acreditavam que o distúrbio do sono era algo com que deveriam aprender a lidar; d) e outros ainda sentiam que a ocorrência não era importante, considerando todo o contexto da doença do câncer (ENGSTROM et al. (1999).

Por meio dos resultados na tabela 9, pode-se perceber onde ocorreu um maior prejuízo do sono e, associando esses resultados com o estudo descrito anteriormente, ressalta-se a necessidade dos profissionais investigarem o padrão do sono em pacientes com câncer. O propósito deve consistir em indicar meios de como adquirir o hábito de um sono saudável, citando-se como exemplos: deitar somente quando sentir sonolência, ou limitar o tempo do cochilo diurno, para não atrapalhar o sono durante a noite.

$\mathrm{Na}$ tabela 10 é apresentada a pontuação global do PSQI. Os escores superiores a cinco pontos indicam má qualidade de sono, sendo a pontuação mínima zero e a máxima de 21 pontos. 
Tabela 10 - Escore Global do Índice de Qualidade do Sono (PSQI), em pacientes com diagnóstico de câncer, que foram submetidos a procedimento cirúrgico nas especialidades de Cabeça e Pescoço e de Urologia, no período de um até o sexto mês de pós-operatório. Uberaba (MG) - 2008.

\begin{tabular}{ccc}
\hline Pontuação Global do PSQI & $\mathbf{N}^{0}$ & $\%$ \\
\hline PSQI $\leq 5$ & 12 & 26,1 \\
PSQI $>5$ & 34 & 73,9 \\
TOTAL & 46 & 100 \\
\hline
\end{tabular}

Ao analisar isoladamente o escore global do PSQI, em relação às respostas fornecidas pelos entrevistados, observa-se que $73,9 \%$ possuem um comprometimento da qualidade subjetiva do sono.

A tabela 11 relaciona média, desvio padrão e nível de significância estatística dos componentes do PSQI, em relação ao escore global do PSQI, obtidos com o teste paramétrico de Análise da Variância (ANOVA) para todos os 46 entrevistados, sendo que somente o componente 5 não foi estatisticamente significante, não tendo sido, por este motivo, incluído na tabela. No anexo E, encontram-se todos os detalhes para cálculos relativos ao PSQI. 
Tabela 11 - Média, desvio padrão e significância estatística dos componentes do PSQI em relação ao Escore Global do PSQI. Uberaba (MG) - 2008.

\begin{tabular}{|c|c|c|c|c|c|}
\hline ESCALA & ESCORES & VARIÁVEL & MEDIA & DESVIO PADRÃO & NIVEL DE SIGNIFICÁNCIA \\
\hline \multirow{24}{*}{ PSQI } & Comp 1 & 0 & 3,50 & 1,31 & $0,000^{*}$ \\
\hline & & 1 & 8,00 & 3,01 & \\
\hline & & 2 & 10,79 & 2,89 & \\
\hline & & 3 & 16,00 & 2,53 & \\
\hline & Comp 2 & 0 & 5,92 & 3,45 & $0,000^{*}$ \\
\hline & & 1 & 5,17 & 2,23 & \\
\hline & & 2 & 10,00 & 3,56 & \\
\hline & & 3 & 12,93 & 3,34 & \\
\hline & Comp 3 & 0 & 4,17 & 1,60 & $0,000^{*}$ \\
\hline & & 1 & 6,35 & 3,24 & \\
\hline & & 2 & 10,00 & 1,41 & \\
\hline & & 3 & 13,29 & 2,91 & \\
\hline & Comp 4 & 0 & 4,80 & 2,62 & $0,000^{*}$ \\
\hline & & 1 & 5,50 & 1,00 & \\
\hline & & 2 & 10,00 & 2,12 & \\
\hline & & 3 & 13,06 & 2,98 & \\
\hline & Comp 6 & 0 & 8,56 & 3,96 & $0,048^{* *}$ \\
\hline & & 1 & 4,00 & - & \\
\hline & & 2 & 13,00 & - & \\
\hline & & 3 & 13,60 & 6,23 & \\
\hline & Comp 7 & 0 & 5,62 & 2,84 & $0,001^{*}$ \\
\hline & & 1 & 8,87 & 3,58 & \\
\hline & & 2 & 11,43 & 3,82 & \\
\hline & & 3 & 13,25 & 6,70 & \\
\hline
\end{tabular}

Quando se analisam as tabelas 6, 7, 8, 9, 10 e 11 de modo conjunto, pode-se compreender porque $73,9 \%$ dos pacientes apresentaram má qualidade de sono (Tabela 10). A análise individual de cada um dos componentes do PSQI, com as questões referentes a eles, pode ser explicitada como segue: a média de 16,00 (DP 2,53) do componente 1 (Tabela 11) revela que os entrevistados tiveram sono muito ruim; o componente 2 informa que, pelo menos mais de três vezes no último mês, o paciente levou mais de trinta minutos para dormir, (média $=12,93$ e DP $=3,34$ ); o componente 3 refere-se à duração do sono em horas e apresenta média de 13,29 (DP 2,91), para a ocorrência de menos de cinco horas de sono; o componente 4, 
com média de 13,06 (DP 2,98) revela que houve eficiência de sono inferior a 65\%; o componente 7 , referente a sonolência diurna e distúrbios durante o dia, resultou em uma média de 13,25, indicando uma ocorrência importante desse problema entre os pacientes.

Desta forma, quando os componentes com seus respectivos significados são avaliados de uma forma conjunta, pode-se entender o relacionamento entre os mesmos. Pois, uma pessoa que tenha dormido menos de cinco horas por noite e levado mais de trinta minutos para dormir é considerada como tendo qualidade de sono ruim, podendo conseqüentemente ter sonolência durante o dia e sentir necessidade para cochilar.

O componente 6, questão que diz respeito ao uso de medicação para dormir, apresentou significância estatística $(p=0,048)$. Nos resultados do estudo por Fortner et al. (2002), entre os pacientes entrevistados que apresentaram um escore global do PSQI menor que cinco, 59\% relataram que fizeram uso de medicações para dormir e desses $30 \%$ utilizaram pelo menos três vezes por semana. Neste estudo, os pacientes relataram que não receberam qualquer tipo de informação de como adquirir um hábito saudável de sono.

\subsection{ANÁLISES ENTRE OS QUESTIONÁRIOS APLICADOS NA AMOSTRA}

Na tabela seguinte também foi aplicado o teste paramétrico ANOVA, sendo apresentados apenas os valores que foram estatisticamente significantes. 
Tabela 12 - Média, desvio padrão e significância estatística das variáveis sociodemográficas e clínicas, em relação ao Escore Global do PSQI. Uberaba (MG) $-2008$.

\begin{tabular}{|c|c|c|c|c|c|}
\hline ESCALA & ESCORES & VARIÁVEL & MEDIA & DESVIO PADRÁO & NIVEL DE SIGNIFICÂNCIA \\
\hline & Renda & 1 & 13,00 & 4,13 & $0,000^{*}$ \\
\hline & & 2 & 8,00 & 3,04 & \\
\hline & & 3 & 6,83 & 4,06 & \\
\hline & & 4 & 3,00 & - & \\
\hline & Escolaridade & 1 & 15,00 & - & $0,040^{\star *}$ \\
\hline Global & & 2 & 9,22 & 3,83 & \\
\hline \multirow[t]{9}{*}{ (PSQI) } & & 3 & 11,00 & 4,76 & \\
\hline & & 4 & 7,33 & 6,11 & \\
\hline & & 5 & 5,00 & 2,16 & \\
\hline & & 6 & 3,50 & 0,71 & \\
\hline & Local do câncer & 1 & 8,25 & 3,82 & $0,023^{\star \star}$ \\
\hline & & 2 & 15,00 & - & \\
\hline & & 3 & 8.50 & 4,95 & \\
\hline & & 4 & 8,30 & 4,19 & \\
\hline & & 6 & 14,60 & 5,37 & \\
\hline
\end{tabular}

As variáveis sociodemográficas e clínicas estão relacionadas no apêndice A, e o teste ANOVA trouxe três escores estatisticamente significantes, sendo eles: a renda, a escolaridade e o local do câncer.

O resultado para a renda e a escolaridade $(p=0,000$ e $p=0,040$ respectivamente), como citado anteriormente na tabela 1, confirmam a importância destes aspectos para a qualidade de sono dos pacientes.

Entretanto, em um estudo realizado por Furlani e Ceolim (2006), os resultados encontrados foram diferentes, pois a escolaridade foi semelhante entre sujeitos com boa e má qualidade de sono habitual (mediana de 4,5 e 5 anos, respectivamente), bem como a renda familiar, predominando a faixa de um a cinco salários mínimos, (que ocorreu em $91,7 \%$ dos entrevistados com boa qualidade de sono habitual e em $84,6 \%$ daqueles com má qualidade de sono habitual). 
Quanto ao local do câncer, que foi estatisticamente significante $(p=0,023)$, sabe-se que ele e o estadiamento da doença são fatores geralmente considerados de importância na literatura. Uma operação de laringectomia total, por exemplo, é um procedimento extremamente invasivo, com seqüelas permanentes para o paciente, e que interferem principalmente nos primeiros meses após o ato cirúrgico com uma série de problemas, como a adaptação do paciente à cânula de traqueostomia, os cuidados que a cânula requer, bem como a impossibilidade de emissão de voz, devido à retirada das cordas vocais (ZAGO et al., 1998). Neste estudo, houve dois casos de câncer de laringe, com média de 8,50.

Os pacientes que foram submetidos a prostatectomia radical (retirada total da próstata) apresentaram uma média de 8,25. Nestes pacientes, uma causa para 0 distúrbio do sono foi o fato de terem de levantar durante a noite para urinar, o que geralmente ocasionava a perda posterior do sono. Alguns pacientes ainda confidenciaram, ao sentirem confiança na pesquisadora, que outro fator era o da impotência sexual ou a preocupação de não conseguirem manter uma relação sexual com a esposa ou companheira. Isto vem ao encontro do que é relatado pelos pacientes no estudo de Penedo et al. (2006). 
Tabela 13 - Média, desvio padrão e significância estatística dos domínios do EORTC, em relação ao Escore Global do PSQI. Uberaba (MG) - 2008.

\begin{tabular}{|c|c|c|c|c|c|}
\hline ESCALA & $\begin{array}{l}\text { DOMINIIO } \\
\text { EORTC }\end{array}$ & $\%$ & MEDIA & $\begin{array}{c}\text { DESVIO } \\
\text { PADRÃO }\end{array}$ & NIVEL DE SIGNIFICÁNCIA \\
\hline \multirow{34}{*}{$\begin{array}{l}\text { Global } \\
\text { (PSQI) }\end{array}$} & \multirow[t]{6}{*}{ EGS } & 50 & 3,5 & 0,71 & $0,030^{*}$ \\
\hline & & 58,3 & 9,89 & 4,17 & \\
\hline & & 66,6 & 8,92 & 3,17 & \\
\hline & & 75 & 10,2 & 5,31 & \\
\hline & & 83,3 & 7,9 & 4,15 & \\
\hline & & 91,6 & 5,50 & 3,54 & \\
\hline & \multirow[t]{6}{*}{ Desempenho de papel } & 0 & 17,33 & 3,06 & 0,000 \\
\hline & & 34 & 6,00 & 3,46 & \\
\hline & & 50 & 8,00 & 4,62 & \\
\hline & & 67 & 10,12 & 3,74 & \\
\hline & & 84 & 11,75 & 3,20 & \\
\hline & & 100 & 6,53 & 3,40 & \\
\hline & \multirow[t]{4}{*}{ Função social } & 17 & 15,00 & 4,24 & 0,007 \\
\hline & & 67 & 9,94 & 4,04 & \\
\hline & & 84 & 7,62 & 4,03 & \\
\hline & & 100 & 7,46 & 3,64 & \\
\hline & \multirow[t]{6}{*}{ Fadiga } & 0 & 5,25 & 2,22 & 0,055 \\
\hline & & 11,1 & 7,80 & 5,85 & \\
\hline & & 22,2 & 8,69 & 3,40 & \\
\hline & & 33,3 & 8,81 & 4,26 & \\
\hline & & 44,4 & 13,33 & 1,53 & \\
\hline & & 55,5 & 13,00 & 7.07 & \\
\hline & \multirow[t]{4}{*}{ Dispnéia } & 0 & 8,39 & 4,19 & 0,032 \\
\hline & & 33 & 14,00 & 1,41 & \\
\hline & & 66 & 7,00 & 4,24 & \\
\hline & & 100 & 15,33 & 4,16 & \\
\hline & \multirow[t]{4}{*}{ Insônia } & 0 & 4,31 & 1,97 & 0,000 \\
\hline & & 33 & 10,00 & 2,37 & \\
\hline & & 66 & 9,55 & 3,59 & \\
\hline & & 100 & 13,80 & 3,88 & \\
\hline & \multirow[t]{4}{*}{ Dificuldade financeira } & 0 & 7,22 & 3,64 & 0,004 \\
\hline & & 33 & 10,18 & 3,92 & \\
\hline & & 66 & 9,00 & 7,07 & \\
\hline & & 100 & 16,67 & 4,16 & \\
\hline
\end{tabular}


Ao cruzar os domínios do EORTC em relação ao escore global do PSQI, utilizando o ANOVA (Tabela 13), observa-se que sete domínios tiveram significância estatística. O EGS $(p=0,030)$ trata das questões relacionadas ao estado de saúde e qualidade de vida. $\mathrm{O}$ desempenho de papel $(\mathrm{p}=0,000)$, com a maior média desta tabela, isto é de 17,33 (DP 3,06), indica que a má qualidade de sono prejudicou e/ou limitou a realização de atividades diárias de trabalho e, inclusive, as atividades de prazer, que geralmente costumam trazer conforto e bem estar às pessoas.

O domínio da função social $(p=0,007)$ informa que a condição física interferiu na vida familiar e nas atividades sociais do indivíduo e a dificuldade financeira, com resultado $p=0,004$, confirmam os resultados encontrados nas tabelas 1 e 2 .

Por esses resultados constatamos que a qualidade do sono e a qualidade de vida estão intimamente relacionadas. O desemprego, por exemplo, é fator para a qualidade de vida e pode afetar a qualidade do sono de um indivíduo devido à preocupação, presente nessa situação, aumentando a latência do sono e os despertares noturnos. Por outro lado, uma pessoa portadora de distúrbio do sono provavelmente sofrerá conseqüências no trabalho, devido a má qualidade do sono (MÜLLER; GUIMARÃES, 2007).

Em um estudo com pacientes que apresentavam insônia, 89\% referiram que os seus distúrbios os afetaram fisicamente; $76,3 \%$ não conseguiram lidar com 0 estresse; $72,3 \%$ tiveram comprometimento relacionado aos aspectos emocionais; $65 \%$ apresentaram problemas em realizar as atividades cotidianas (trabalho, como exemplo) e 64,7\% queixaram-se que não conseguiam se concentrar (DAVIDSON et al., 2002).

A dispnéia apresentou um $p=0,032$. Este resultado condiz com o estudo de Viola et al. (2008), onde a dispnéia foi um sintoma comum e estressante, vivenciada 
pelos pacientes com câncer avançado e ocorrendo em 19 a $51 \%$ dos seus respondentes. No presente estudo, a dispnéia pode ter sido relacionada com dois casos de câncer avançado e dois casos pós-laringectomia.

O domínio de insônia, que é um dos causadores de distúrbios no padrão do sono, e que é o tema central deste estudo, teve $p=0,000$ e média de 13,80 (DP $3,88)$.

Os resultados discutidos acima dão segurança para afirmar que, neste estudo, os pacientes apresentaram uma má qualidade de sono e isto vem em conjunto com o próximo domínio, a fadiga $(p=0,055)$ que, juntamente com todos os outros domínios descritos anteriormente, não poderia deixar de ser significante. Existem vários estudos descrevendo a fadiga em pacientes com câncer, como sendo um sintoma comum durante e após os tratamentos oncológicos.

Nail (2002) afirma que a fadiga é a deficiência na habilidade em manter a atenção, o foco mental ou mesmo a concentração e que é uma condição presente em pacientes com câncer. O sono é considerado restaurativo e, se for inadequado ou não terapêutico, a fadiga que deveria ser aliviada pelo sono pode se tornar crônica (LEE, 2001).

A fadiga é diretamente influenciada pela qualidade do sono e do quanto este é interrompido pelas variáveis fisiológicas (como freqüência de nictúria e dispnéia), ou pelas variáveis externas, como preocupações financeiras, prejuízo no desempenho familiar e social (ANDERSON et al., 2003). Na pesquisa de Hoffman et al. (2007), dos 177 pacientes que estavam empregados, $77 \%$ perderam um dia pelo menos no trabalho como resultado de fadiga. Esses resultados mostram que a fadiga e os distúrbios do sono também acarretam problemas no vínculo empregatício e situação financeira. 
Coelho e Sawada (1999), ao indagarem a que os pacientes com câncer atribuíam os sintomas de cansaço, identificaram $4(36,4 \%)$ pacientes com relato de preocupação com a doença; 2 (18,2\%) atribuíram à ansiedade, rotinas diárias, radioterapia e cirurgia; $1(9,1 \%)$ relacionou ao estresse, trabalho, depressão e tensão emocional. Os autores relataram ainda que os sintomas da fadiga, entre os pacientes com câncer, são de grande importância para a reabilitação, pois afetam diretamente a qualidade de vida.

A fadiga relacionada ao câncer e aos distúrbios no padrão do sono estão associados. A prevalência, bem como a sua associação, dependem de uma avaliação conjunta destes sintomas antes do diagnóstico e do tratamento, durante e após o tratamento (ROSCOE et al., 2007).

O instrumento de Índice de Qualidade de Sono de Pittsburg (PSQI) é utilizado em pesquisas em todo o mundo e permite detectar, por meio de seus componentes, possíveis causas de má qualidade de sono. Sua utilidade na prática é a de mensurar a qualidade do sono, sendo esta uma forma útil de propiciar uma forma de intervir em cuidados individualizados.

Desta maneira, com base nos resultados apontados neste estudo, o profissional de saúde pode assumir que, de fato, o distúrbio do sono será um fator presente nos pacientes cirúrgicos oncológicos. Aqui convém dissertar um pouco sobre o achado que o tempo delimitado na pesquisa, de um até o sexto mês de pósoperatório, não demonstrou nível de significância entre os pacientes entrevistados. $\mathrm{Na}$ fase inicial da pesquisa, quando a mesma foi delineada, foi suposto que esta variável fosse apresentar significância estatística, por representar um período de tempo que muitas vezes requer adaptações físicas e sociais do paciente. Como isto 
não ocorreu, pode-se aceitar que, no decorrer dos cinco subperíodos analisados (Tabela 1), não há alteração significante relativa aos dados avaliados neste estudo.

Algumas limitações do presente estudo podem ser apontadas, como a amostra, que foi bastante heterogênea, pois as operações de Cabeça e Pescoço e as de Urologia são bastante distintas, quando comparadas entre si. Um outro fator é que as entrevistas foram realizadas em um mesmo local, e pode ser que o regionalismo tenha interferido nos resultados. Ainda pode-se mencionar o fato da amostra ter sido composta por 46 pacientes, o que pode ser considerado um número reduzido, quando comparado à expectativa do grande número de pacientes que deve ser atendido com câncer em 2008, segundo previsão do INCA. Tais limitações podem ser superadas em novas investigações. A realização de estudo prospectivo talvez possa ser um método mais apropriado, para validar os achados desta pesquisa, bem como aperfeiçoar estratégias, a fim de detectar distúrbios do sono e poder oferecer um suporte mais adequado aos pacientes que estiverem apresentando este problema.

O estudo revelou resultados inovadores no âmbito da pesquisa científica e alguns avanços podem ser apontados. Durante a fase de revisão bibliográfica, não foi encontrada nenhuma publicação que identificasse perturbações do sono em pacientes cirúrgicos oncológicos, nas especialidades de Cabeça e Pescoço e de Urologia, e muito menos que associasse distúrbios do sono com qualidade de vida do paciente com câncer.

Em nível nacional, pela primeira vez, foi determinada a prevalência do distúrbio de sono em pacientes submetidos a procedimento cirúrgico para câncer, nas especialidades de Cabeça e Pescoço e de Urologia. Uma alta porcentagem de pacientes, isto é $73,9 \%$, apresentou má qualidade de sono pelo PSQI, e ao realizar 
os testes de correlação entre o Estado Geral de Saúde (EGS) com o escore global do PSQI e do domínio de insônia do EORTC com o escore global do PSQI, r=-0,339 e 0,710 respectivamente, foi demonstrada existência de correlação significativa.

Diante desses resultados, pode-se concluir que os distúrbios no padrão do sono foram uma ocorrência freqüente neste grupo de pacientes oncológicos.

Apesar dos questionários PSQI e EORTC, utilizados neste estudo, serem de fácil aplicabilidade nos pacientes oncológicos com distúrbios do sono, é necessário um conhecimento científico para saber interpretar os resultados. Dessa forma, acreditamos que esses instrumentos não são viáveis para uso cotidiano na prática pelos profissionais, em especial pela equipe de enfermagem, por não serem possuídas as informações de interpretação que os mesmos requerem. Uma interpretação errada provavelmente ocasionará uma assistência profissional inapropriada. No entanto, considerando que a meta das intervenções de reabilitação do paciente cirúrgico oncológico é a sobrevivência com qualidade de vida, para o seu alcance é necessário que a avaliação do sono e da qualidade de vida sejam parâmetros focalizados pelos enfermeiros, no exercício das suas funções.

Algumas recomendações para adquirir um hábito de sono saudável incluem:

$\checkmark$ Manter um horário regular para dormir e acordar (mesmo nos finais de semana).

$\checkmark$ Deitar somente quando estiver sonolento.

$\checkmark$ Levantar da cama quando não conseguir adormecer no período de 15-20 minutos e ir para outro cômodo, permanecendo em atividade não estimulante até sentir sonolência.

$\checkmark$ Dormir apenas o necessário. 
$\checkmark$ Realizar exercícios físicos regulares que estimulam o sono, o que deve ser feito 4-6 horas antes de deitar.

$\checkmark$ Fazer um lanche leve antes de deitar; evitar alimentos pesados.

$\checkmark$ Reduzir nível de ruído e de luz.

$\checkmark$ Evitar estimulantes, como nicotina, alimentos e bebidas que contêm cafeína, de 4 a 6 horas antes de deitar (exemplos: chocolate, café e refrigerantes).

$\checkmark$ Evitar ingestão de bebidas alcoólicas, pois provocam despertares noturnos.

$\checkmark$ Evitar cochilar durante o dia, ou então limitar o tempo para 20 minutos e evitar isto após as 15 horas. 
6 CONSIDERAÇÕES FINAIS 
Os distúrbios no padrão do sono ocorrem com freqüência em sobreviventes do câncer e geralmente levam aos problemas crônicos, que interferem diretamente na qualidade de vida.

O presente estudo encontrou níveis estaticamente significantes de fatores relativos a distúrbio do padrão do sono em sobreviventes de câncer, submetidos a procedimento cirúrgico nas especialidades de Cabeça e Pescoço e de Urologia, sendo eles:

$\checkmark$ o escore global do instrumento de Índice de Qualidade de Sono de Pittsburg (PSQI) revelou que 73,9\% dos pacientes apresentaram má qualidade de sono;

$\checkmark \quad$ o teste de Confiabilidade Alfa de Cronbach para as escalas do PSQI e do EORTC revelou elevada consistência interna e homogeneidade para ambas escalas, obtendo-se para o PSQI o valor de 0,794 e para o EORTC, o valor de 0,8139;

$\checkmark$ o teste de correlação entre o Estado Geral de Saúde (EGS) e o escore global do PSQI apresentou um $r=-0,339$, demonstrando existência de correlação significativa. O domínio de insônia do EORTC e o escore global do PSQI também apresentaram correlação significativa, com $r=0,710$.

$\checkmark$ as variáveis que se mostraram estatisticamente significantes em relação aos distúrbios do sono foram: renda, escolaridade e local do câncer, para os dados do questionário sociodemográfico e clínico; EGS, desempenho de papel, função social, insônia, fadiga, dispnéia e dificuldade financeira, para os domínios do EORTC. 
Os distúrbios no padrão do sono em pacientes oncológicos constituem ainda um foco de pouca atenção pelos profissionais da saúde, especialmente pela enfermagem, e com isso esta importante ocorrência está sendo negligenciada. Este posicionamento talvez ocorra por se acreditar que os distúrbios sejam um sintoma esperado entre os pacientes com câncer e, desta forma, eles recebem menor atenção que o tratamento propriamente dito. Como decorrência, os profissionais não adquirem conhecimento adequado para o diagnóstico e subseqüentemente para a profilaxia e terapêutica das complicações associadas a este problema. 


\section{REFERÊNCIAS}


ALVAREZ, G. G.; NAJIB, T. A. The impact of daily sleep duration on health: a review of the literature. Prog Cardiovasc Nurs, v. 19, n. 2, p. 56-59, 2004.

ANCOLI-ISRAEL, S.; MOORE, P. J.; JONES, V. The relationship between fatigue and sleep in cancer patients: a review. Eur J Cancer Care, v. 10, n. 4, p. 245-255, dec. 2001.

ANDERSON, K. O.; GETTO, C. J.; MENDOZA, T. R.; PALMER, S. N.; WANG, X.S.; REYES-GIBBY, C. C.; CLEELAND, C. S. Fatigue and sleep disturbance in patients with cancer, patients with clinical depression, and community-dwelling adults. J Pain Symptom Manage, v. 25, n. 4, p. 307-318, apr. 2003.

BARBOSA, M. H. Barreira microbiana das máscaras cirúrgicas descartáveis segundo o seu tempo de utilização. 2003. Tese (Doutorado em Enfermagem) Escola de Enfermagem da Universidade de São Paulo, São Paulo, 2003.

BECK, S. L.; DUDLEY, W. N.; BARSEVICK A. Pain, Sleep Disturbance, and Fatigue in Patients With Cancer: Using a Mediation Model to Test a Symptom Cluster.

Oncology Nursing Forum, v. 32, n. 3, p. 542-565, 2005.

BONASSA, E. M. A. Enfermagem em terapêutica oncológica. 3 ed. São Paulo: Atheneu, 2005. $538 \mathrm{p}$.

BRASIL. Ministério da Saúde. Secretaria de Atenção à Saúde. Instituto Nacional de Câncer. Coordenação de Prevenção e Vigilância de Câncer. Estimativas 2008: Incidência de Câncer no Brasil. Rio de Janeiro: INCA, 2007. Disponível em:< http://www.inca.gov.br/estimativa/2008/versaofinal.pdf>. Acesso em: 15 fev. 2008.

BURKE, M. B. Cancer: related fatigue and sleep disturbance. ANJ, v. 106, n. 3, supp, p. 72-77, mar. 2006.

BUYSSE, D.J.; REYNOLDS, C. F.; MONK, T, H.; BERMAN, S. R.; KUPFER, D. J. The Pittsburgh sleep quality index: a new instrument for psychiatric practice and research. Psychiatry Research, v. 28, n. 2, p. 193-213, 1989

CELLA. D.; KALLICH, J.; MCDERMOTT, A.; XU, X. The longitudinal relationship of hemoglobin, fatigue and quality of life in anemic cancer patients: results from five randomized clinical trials. Annals of oncology, v. 15, n. 6, p. 979-986, 2004. 
CEOLIM, M. F. Padrões de atividades e de fragmentação do sono em pessoas idosas. 1999. $287 \mathrm{f}$. Tese (Doutorado em Enfermagem) - Escola de Enfermagem de Ribeirão Preto da Universidade de São Paulo, Ribeirão Preto, 1999.

COELHO, F. M. R.; SAWADA, N. O. A fadiga nos pacientes com câncer de laringe. Rev.latino-am.enfermagem, Ribeirão Preto, v. 7, n. 5, p. 103-107, 1999.

CUNHA, M. C. B. Qualidade do sono em diabéticos do tipo 2. 2006. $102 \mathrm{f}$. Dissertação (Mestrado em Enfermagem Fundamental) - Escola de Enfermagem de Ribeirão Preto da Universidade de São Paulo, Ribeirão Preto, 2006.

DAVIDSON, J. R.; MACLEANA, A. W.; BRUNDAGEB, M. D.; SCHULZEC, K. Sleep disturbance in cancer patients. Social Science \& Medicine, v. 54, p. 1309-1321, 2002.

DAWSON, L.; BROCKBANK, K.; CARR, E. C. J.; BARRET, R. F. Improving patient's postoperative sleep: a randomized control study comparing subcutaneous with intravenous patient-controlled analgesia. Journal of Advanced Nursing, v. 30, n . 4, p. 875-881, 1999.

ENGSTROM, C. A.; STROHL, R. A.; ROSE, L.; LEWANDOWSKI, L.; STEFANEK, M. E. Sleep alterations in cancer patients. Cancer Nurs, v. 22, n. 2, p.143-148, apr. 1999.

FAULL, C.; HIRSCH, C. Symptom management in palliative care. Prof Nurse, v. 16, n. 1 , p. $840-843$, oct. 2000.

FERNSEBNER, B. Sleep deprivation in patients. AORN J, v. 37, n. 1, p. 35-42, jan. 1983.

FISHER, P. T. Survivorship. CJON, v. 10, n. 1, p. 93-98, 2006.

FORTNER, B. V.; STEPANSKI, E. J.; WANG, S. C.; KASPROWICZ, S.;

DURRENCE, H. H. Sleep and quality of life in Breast Cancer Patients. Journal of

Pain and Symptom Management, v. 24, n. 5, p. 471-480, 2002.

FURLANI, R.; CEOLIM, M. F. Qualidade do sono de mulheres portadoras de câncer ginecológico e mamário. Rev Latino-am Enfermagem, Ribeirão Preto, v. 14, n. 6, p. 45-52, 2006. 
GRACI, G. Pathogenesis and Management of Cancer-Related Insomnia. The Journal of Supportive Oncology, v. 3, n. 5, set./oct. 2005. Disponível em: <http://www.supportiveoncology.net/journal/articles/0305349.pdf >. Acesso em: 15 fev. 2008.

GUIMARÃES, R. M.; ROMANELLI, G. A inserção de adolescentes no mercado de trabalho através de uma ONG. Psicologia em Estudo, Maringá, v. 7, n. 2, p. 117126, jul./dez. 2002. Disponível em:<http://www.scielo.br/pdf/pe/v7n2/v7n2a14.pdf>. Acesso em: 17 março 2008.

HAYLOCK, P. J.; MITCHELL, S. A.; COX, T.; TEMPLE, S. V.; CURTISS, C. P. The cancer survivor's prescription for living. ANJ, v. 107, n. 4, p. 58-70, apr. 2007.

HEWITT, M. E.; SHELDON, H.; STOVALL, G. E. From Cancer Patient to Cancer Survivor: lost in transition. Washington: National Academies Press, 2005. 536 p.

HOFFMAN, M.; RYAN, J. L.; MOSELEY, C. D. F.; PIERRE, P. J.; MORROWA, G. R. Cancer-Related Fatigue: The Scale of the Problem. The Oncologist, n. 12, (suppl 1), p. 4-10, 2007.

JOHNSTON, P.; SPENCE, A. J. Oncology: oxford handbook of clinical medicine. 2003. Publisher: Oxford University Press. 560 p.

KAMEO, S. Y. Qualidade de vida do paciente com estomia intestinal secundária ao câncer colo-retal. 2006. 119 f. Dissertação (Mestrado em Enfermagem Fundamental) - Escola de Enfermagem de Ribeirão Preto da Universidade de São Paulo, Ribeirão Preto, 2006.

KAPLOW, R. Sleep deprivation and psychosocial impact in acutely III cancer patients. Crit. Care Nurs Clin North Am, v. 17, n. 3, p. 225-237, 2005.

LAMB, M. A. The sleeping patterns of patients with malignant and nonmalignant diseases. Cancer Nurs, v. 5, n. 5, p. 389-396, oct. 1982.

LEE, K. A. Sleep and fatigue. Annu Rev Nurs Res, v.19, p. 249-73, 2001.

MACAVOY, S.; MORITZ, D. Nursing diagnoses in an oncology population. Cancer Nurs, v. 15, n. 4, p. 264-270, aug. 1992. 
MARTINS, G. A. Sobre confiabilidade e validade. RBGN, v. 8, n. 20, p.1-12, 2006.

MAXWELL, M. Malignant effusions and edemas: cancer nursing. 4. ed. Boston: Jones and Bartlett, 1997. $415 \mathrm{p}$.

MERCADANTE, S.; GIRELLI, D.; CASUCCIO, A. Sleep disorders in advanced cancer patients: prevalence and factors associated. Support Care Cancer, v. 12, p. 355-359, 2004.

MONGA, U.; KERRIGAN, A. J.; THORNBY, J.; MONGA, T. N.; ZIMMERMANN, K. P. Longitudinal study of quality of life in patients with localized prostate cancer undergoing radiotherapy. JRRD, v. 42, n. 3, p. 391-400, 2005.

MOTA, D. D. C. F. Fadiga do doente com câncer colo-retal: fatores de risco e preditivos. 2008. Tese (Doutorado em Enfermagem)- Escola de Enfermagem da Universidade de São Paulo, São Paulo, 2008.

MÜLLER, M. R.; GUIMARÃES, S. S. Impacto dos transtornos do sono sobre o funcionamento diário e a qualidade de vida. Estudos de Psicologia, Campinas, v. 24, n. 4, p. 519-528, 2007.

NAGEL, C. L.; MARKIE, M. B.; RICHARDS, K. C.; TAYLOR, J. L. Sleep promotion in hospitalized elders. Medsurg Nursing, v. 12, n. 5, p. 279-289, 2003.

NAIL, L. M. Fatigue in Patients With Cancer. Oncology Nursing Forum, v. 29, n. 3, p. 537-544, 2002.

NATIONAL CANCER INSTITUTE. Sleep disorders. mar. 2006. Disponível em: < http://www.cancer.gov/cancertopics/pdq/supportivecare/sleepdisorders/patients/>. Acesso em: 17 maio 2007.

NORMAS e recomendações do INCA/MS / INCA/MS - Norms and Recommendations. Controle de sintomas do câncer avançado em adultos. Revista Brasileira de Cancerologia, Rio de Janeiro, v. 46, n. 3, p. 243-256, 2000.

Disponível em:<http://www.inca.gov.br/rbc/n_46/v03/pdf/normas.pdf>. Acesso em: 18 maio 2007.

NORUSIS, M. J. SPSS/PC: professional statistics. Chicago: SPSS, 1992. 
O'DONNELL, J. F. Insomnia in Cancer Patients. Insomnia in cancer patients. Clinical Cornerstone, v. 6, suppl 1, p. 6-14, 2004.

OLSON, K.; TURNER, A. R.; COURNEYA, K. S.; FIELD, C.; MAN, G.; CREE, M.; HANSON, J. Possible links between behavioral and physiological indices of tiredness, fatigue, and exhaustion in advanced cancer. Support Care Câncer, v. 16, p. 241-249, 2008.

ONS - ONCOLOGY NURSING SOCIETY. 2003-2005 ONS Research Agenda. 2003. Disponível em: <

http://www.ons.org/research/information/documents/pdfs/talking05.pdf>. Acesso em: 05 set. 2007.

ONS - ONCOLOGY NURSING SOCIETY. 2005-2009 ONS Research Agenda. 2007. Disponível em: < http://www.ons.org/research/information/documents/pdfs/talking05.pdf>. Acesso em: 05 set. 2007.

PASSIK, S. D.; WHITCOMB, L. A.; KIRSH, K. L.; THEOBALD, D. E. An unsuccessful attempt to develop a single-item screen for insomnia in cancer patients. $\mathbf{J}$ Pain Symptom Manage, v. 25, n. 3, p. 284-287, mar. 2003.

PENEDO, F. J.; DAHN, J. R.; SHEN, B. J.; SCHNEIERMAN, N.; ANTONI, M. H. Ethnicity and determinants of quality of life after prostate cancer treatment. Urology, n. 67 , p. 1022-1027, 2006.

POLIT, D. F.; BECK, C. T.; HUNGLER, B. P. Fundamentos de pesquisa em enfermagem: métodos, avaliação e utilização. 5. ed. Porto Alegre: Artes Médicas, 2004.

REDEKER, N. S.; LEV, E. L.; RUGGIERO, J. Insomnia, Fatigue, anxiety, depression, and quality of life of cancer patients undergoing chemotherapy. Sch Inq Nurs Pract; v. 14, n. 4 , p. $275-90,2000$.

ROSCOE, J. A.; KAUFMAN, A. M.; RUSBY, A. S. E.; PALESH, O. G.; RYAN, J. L.; KOHLI, S.; PERLIS, M. L.; MORROWA, G. R. Cancer-related fatigue and sleep disorders. The Oncologis, n. 12(suppl 1), p. 35-42, 2007.

SAVARD, J.; MORIN C. M. Insomnia in the context of cancer: a review of a neglected problem. J Clin Oncol, v. 19, p. 895-908, 2001. 
SELA, R. A.; WATANABE, S.; NEKOLAICHUK, C. L. Sleep disturbances in palliative cancer patients attending a pain and symptom control clinic. Palliative and

Supportive Care, v. 3, p. 23-31, 2005.

SHEELY, L. C. Sleep disturbances in hospitalized patients with cancer. Oncol Nurs Fórum, v. 23, n. 1, p.109-111, jan./feb. 1996.

SILBERFARB, P. M. Psychiatric treatment of the patient during cancer therapy. CA: Cancer J Clin, v. 38, p. 133-137, 1988.

SIMEIT, R.; DECK, R.; MARX, B. C. Sleep management training for cancer patients with insomnia. Support Care Cancer, 12, p. 176-183, 2004.

TRANMER, J. E.; MINARD, J.; FOX, L. A.; REBELO, L. The sleep experience of medical and surgical patients. Clinical Nursing Research, v. 12, n. 2, p. 159-173, 2003.

VACHANI, C. Insomnia in the patient with cancer. Oncolink - Abramson Cancer Center of the University of Pennsylvania. apr. 2007. Disponível em: < http://www.oncolink.com/coping/article.cfm?c=5\&s=69\&ss=116\&id=709>. Acesso em: 17 maio 2007.

VARRICCHIO, C. G. A cancer source book for nurses. 8. ed. Canada: Jones and Bartler Publishers, 2004. 580 p.

VENA, C.; PARKER, K.; CUNNINGHAM, M.; CLARK, J.; MCMILLAN, S. Sleep-wake disturbances in people with cancer part I: an overview of sleep, sleep regulation, and effects of disease and treatment. Oncology Nursing Forum, v. 31, n. 4, p. 735-746, $2004 a$.

VENA, C.; PARKER, K.; CUNNINGHAM, M.; CLARK, J.; MCMILLAN, S. Sleep-wake disturbances in people with cancer part II: evaluating the evidence for clinical decision making. Oncology Nursing Forum, v. 31, n. 4, p. 747-767, 2004b.

VIOLA, R.; KITELEY, C.; LLOYD, N. S.; MACKAY, J. A.; WILSON, J.; WONG, R. K. $S$. The management of dyspnea in cancer patients: a systematic review. Support Care Câncer, v.16, p. 329-337, 2008.

WEISSMAN, D. E.; JANJAN, N.; BYHARDT, R. W. Assessment of pain during head and neck irradiation. J Pain Symptom Manage, v. 4, n. 2, p. 90-95, jun. 1989. 
ZAGO, M. M. F.; SAWADA, N. O.; STOPA, M. J. R.; MARTINEZ, E. L. O significado cultural de ser laringectomizado. Revista Brasileira de Oncologia, Rio de Janeiro, v. 44, n. 2, p. 139-145, 1998. 


\section{APÊNDICES}




\title{
APÊNDICE A - Carta de Solicitação
}

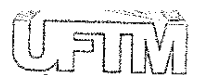 \\ MINISTERIO DA EDUCAÇÃO
UNIVERSIDADE FEDERAL DO TRIÂNGULO MINEIRO - Uberaba-MG
}

CARTA DE SOLICITAÇÃO

Uberaba (MG), 03 de julho de 2007.

\section{IIma. Dra. Ivone Elizabeth Ferreira Leboreiro}

Diretora Clínica da Associação de Combate ao Câncer do Brasil Central

Venho por meio desta solicitar vossa autorização, para desenvolver projeto de pesquisa intitulado: "Distúrbio nos padrões de sono em pacientes oncológicos". Os sujeitos
da pesquisa serão os pricto de urologia que estejam pacientes que vierem para retomo ambulatorial de cabeça e pescoço e

ate dois meses de pós-operatório. denominado Indice qualidade do sono nos pacientes, será utilizado um questionário

Q

Será solicitada aos pacientes a amuência para participação no estudo, após terem sido esclarecidos sobre o tema, objetivo e finalidade do trabalho, bem como sobre a garantia do anonimato, sigilo e privacidade. Solicitar-se-á por escrito o termo de Consentimento Livre e Esclarecido.

Os objetivos da pesquisa são: hospitalar:

1-Avaliar os padrões do sono em pacientes cirúrgicos oncológicos, após a alta

2- Identificar as diversas perturbações de sono a que estão expostos os pacientes cirúrgicos oncológicos;

3- Identificar o impacto que a falta de sono acarreta para a recuperação destes pacientes, até o segundo mês de pós-operatório.

Espera-se, com este estudo, contribuir para discussão e reflexão a respeito do distúrbio do sono nos pacientes oncológicos, com base na análise e categorização dos dados a serem obtidos. Tem-se o intuito de ampliar a visão da equipe de enfermagem sobre o tema, e desenvolver atividades que possam melhorar a qualidade de vida dos pacientes.

Agradeço desde já pela sua atenção.
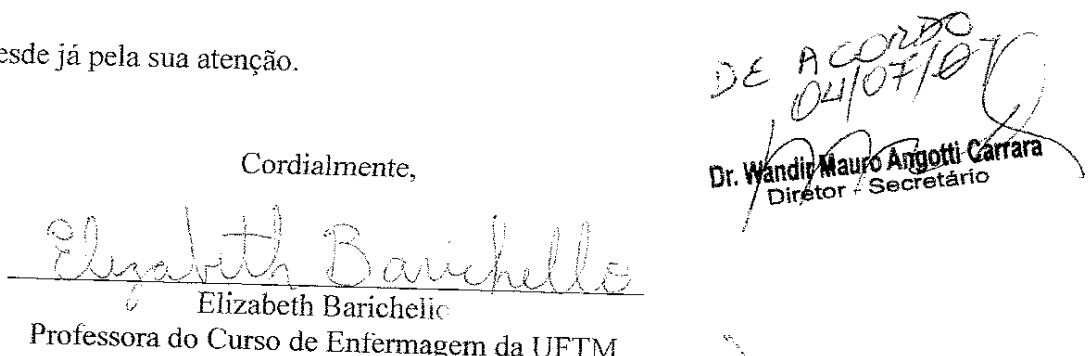

Professora do Curso de Enfermagem da UFTM 
APÊNDICE B - Termo de Consentimento Livre e Esclarecido

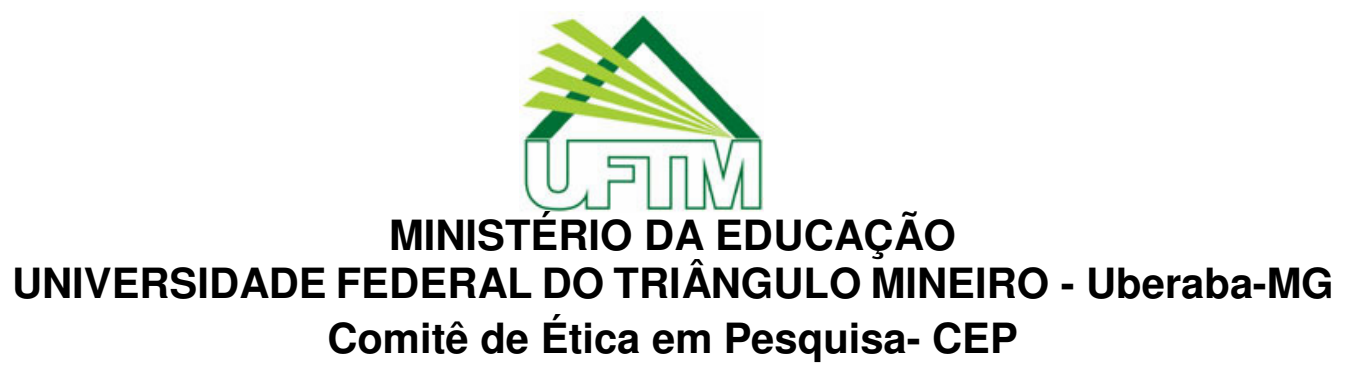

Termo de Esclarecimento

TíTULO DO PROJETO: Distúrbios no padrão do sono em pacientes submetidos à cirurgia oncológica

Estamos desenvolvendo uma pesquisa intitulada "Distúrbio nos padrões de sono em pacientes oncológicos", que tem como objetivo: Complementar os conhecimentos sobre o sono e seus distúrbios, entre pacientes oncológicos, avaliando o sono entre um grupo de pacientes. Desta forma, estamos solicitando sua autorização para participar deste estudo e, caso concorde, será preciso que responda a um questionário. Não será feito nenhum procedimento, que lhe traga qualquer desconforto ou risco à sua saúde. Você poderá ter todas as informações que quiser e poderá não participar da pesquisa ou retirar seu consentimento a qualquer momento, sem prejuízo no seu atendimento. Pela sua participação no estudo, você não receberá qualquer valor em dinheiro, mas terá a garantia de que todas as despesas necessárias para a realização da pesquisa não serão de sua responsabilidade. Seu nome não aparecerá em qualquer momento do estudo, pois você será identificado com um número.

Termo de consentimento livre, após esclarecimento.

$\mathrm{Eu}$, li e/ou ouvi o esclarecimento acima e compreendi para que serve o estudo e qual procedimento a que serei submetido. A explicação que recebi esclarece os riscos e benefícios do estudo. Eu entendi que sou livre para interromper minha participação a qualquer momento, sem justificar minha decisão e que isso não afetará meu tratamento. Sei 
que meu nome não será divulgado, que não terei despesas e não receberei dinheiro por participar do estudo. Eu concordo em participar do estudo.

Uberaba

(.................................

$\overline{\text { Assinatura do voluntário ou seu responsável legal }}$ Documento de Identidade

Assinatura do pesquisador responsável Assinatura do pesquisador orientador

Telefone de contato do pesquisador: (034)3318-5484

Em caso de dúvida em relação a esse documento, você pode entrar em contato com o Comitê de Ética em Pesquisa da Universidade do Triângulo Mineiro, pelo telefone 3318-5854 
APÊNDICE C - Instrumento A: variáveis sociais e clínicas

1- Qual a sua idade?

2-Sexo: 1- ( ) Masculino 2- ( ) Feminino

3- Renda mensal:

1-( ) até 1 salário mínimo 2-( ) 1 a 2 salários mínimos

3- ( ) 2 a 4 salários mínimos 4- ( ) mais 4 salários mínimos

4- Escolaridade:

1- ( ) Analfabeto 2- ( $) 1^{\circ}$ grau incompleto 3- ( $) 1^{\circ}$ grau completo

4- ( ) $2^{\circ}$ grau incompleto 5- ( ) $2^{\circ}$ grau completo

5- Estado civil:

1-( ) casado 2-( ) solteiro 3-( ) divorciado

4-( ) viúvo 5- ( ) separado 6-( ) amasiado

6- O seu trabalho é:

$\begin{array}{lll}\text { 1- ( ) tempo integral } & \text { 2- ( ) meio período } & 3-(\text { ) aposentado } \\ \text { 4- ( ) desempregado } & 5-(\text { ) do lar } & 6-(\text { ) outro: }\end{array}$

7 - O que causou ou contribuiu para seu recente distúrbio do sono?

Assinalar quantos itens forem aplicáveis.

( ) barulho ou ruídos

( ) dor ou desconforto

( ) pensamentos

( ) morte de alguém próximo

( ) problemas de relacionamento

( ) alcoolismo

( ) cafeína

( ) pensamentos sobre a minha morte

( ) eventos positivos (ex: viagens, celebrações familiares)

( ) diagnóstico de câncer

( ) efeitos físicos do câncer

( ) efeitos físicos de outras doenças. (especificar)

( ) medicação ou tratamento, (especificar)

( ) sentimentos, (especificar)

( ) temperatura climática, (especificar) 
( ) levantar par ir ao banheiro

( ) outros, (especificar)

8- Preocupações com:

( ) minha família ou amigos

( ) trabalho

( ) situação financeira

( ) meu modo de viver

( ) como vou realizar minhas atividades

( ) minha saúde

( ) os efeitos colaterais do meu tratamento

( ) minha aparência

( ) as decisões que tenho de tomar quanto ao meu tratamento

( ) locomoção para ir ao local de tratamento

( ) Eu não sei

9- Quando foi que você soube que estava com câncer ?

Favor estimar o mês e o ano mês ano

10- Qual era o local do câncer?

1-( ) próstata 2- ( ) bexiga 3- ( ) laringe 4- ( ) tireóide 5- ( ) lábio

6- Outro:

11- há quanto tempo realizou cirurgia?

1- ( ) até 2 meses

4-( ) 4 a 5 meses

2- ( ) 2 a 3 meses

5-( ) 5 a 6 meses

3- ( ) 3 a 4 meses

12- Você foi submetido(a) a algum tratamento de câncer antes da cirurgia?

( ) Sim, que tipo? ( ) quimioterapia ( ) radioterapia ( ) não

13-Você foi submetido(a) a algum tratamento de câncer após a cirurgia?

( ) Sim, que tipo? ( ) quimioterapia ( ) radioterapia ( ) não 
ANEXOS 


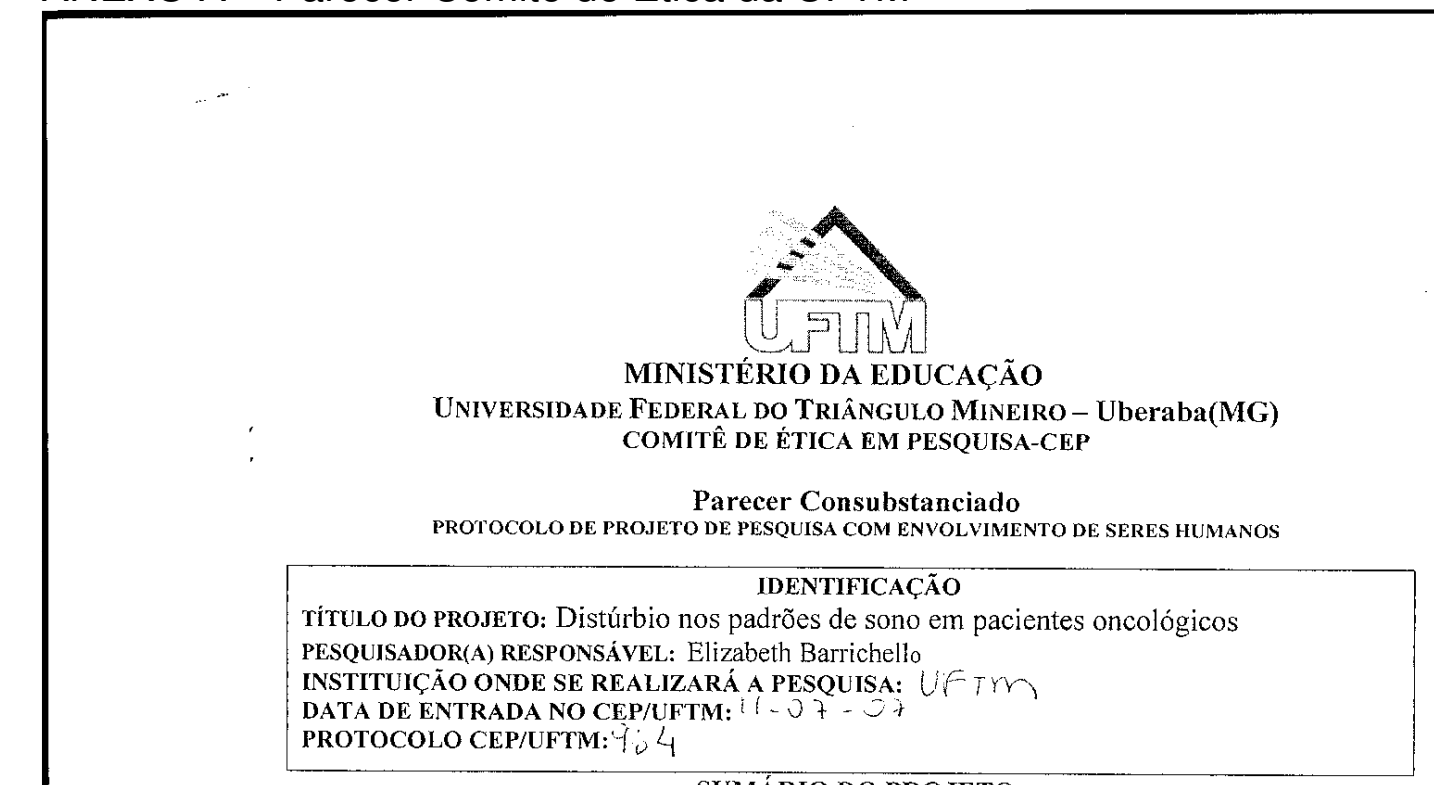

SUMÁRIO DO PROJETO

\section{OBJETIVOS}

1- Avaliar os padrões do sono em pacientes cirúrgicos oncológicos após a alta hospitalar.

2- Identificar as diversas perturbações de sono a que estão expostos os pacientes cirúrgicos oncológicos;

3- Identificar o impacto que a falta de sono acarreta para a recuperação destes pacientes até o quinto mês de pós-operatório;

\section{JUSTIFICATIVA}

A literatura relacionada ao sono do paciente oncológico é de certo modo escassa e, no levantamento bibliográfico realizado deste tema, não foi encontrada nenhuma pesquisa de âmbito nacional. Com isso, justifica-se a realização do presente estudo, por se acreditar que os seus resultados irão colaborar com outras pesquisas que buscam investigar sobre este assunto

\section{DESCRIÇÃO E CARACTERIZAÇÃO DA AMOSTRA}

Os sujeitos da pesquisa serão os pacientes que vierem para retorno ambulatorial de cabeça e pescoço e urologia de uma instituição pública, em um município do interior de Minas Gerais, que estejam com até dois meses de pós-operatório.

Critérios de inclusão:

Pacientes que foram submetidos a cirurgia de cabeça e pescoço e urologia com até dois meses de pós-operatório, que vierem para retorno ambulatorial no período de setembro a dezembro de 2007 ; de ambos os sexos; maiores de 18 anos; que possam se comunicar e que aceitarem participar do estudo por meio de assinatura do termo de consentimento livre e esclarecido

Critérios de exclusão: serão excluídos todos os pacientes que tiverem mais de dois meses de pósoperatório e aqueles que não quiserem fazer parte do estudo

\section{ADEQUACÃO DA METODOLOGIA}

Caracterização do estudo e do local de sua realização

Este estudo consiste numa pesquisa exploratória, com delineamento observacional-transversal. A pesquisa exploratória tem início com a delimitação de um fenômeno de interesse - no caso, a privação de sono em pacientes cirúrgicos oncológicos. No entanto, mais do que simplesmente observar e descrever o fenômeno, a pesquisa exploratória investiga a sua natureza complexa e os outros fatores com os quais ele está relacionado. Pelo delineamento observacional-transversal, os

$$
\begin{aligned}
& \text { Avenida Frei Paulino, } 30-2^{\circ} \text {, andar -CEA - Abadia - 38025-180-llberaba-MG - Telefax }\left(0^{* * 34) 3318-5854}\right. \\
& \text { E mail cepoprodepe.fmtm.br }
\end{aligned}
$$




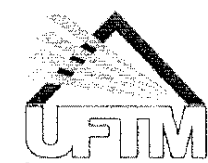

MINISTÉRIO DA EDUCAÇÃO

UniVERSidAde Federal do TriângUlo Mineiro - Uberaba(MG) COMITÊ DE ÉTICA EM PESQUISA-CEP

Parecer Consubstanciado

PROTOCOLO DE PROJETO DE PESOUISA COM ENYOLYIMENTO DE SERES HUMANOS

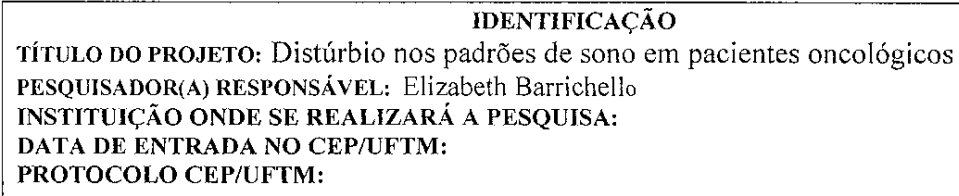

IDENTIFICACÃO

TÍrTULO DO PROJETO: Distúrbio nos padrões de sono em pacientes oncológicos PESQUISADOR(A) RESPONSÁVEL: Elizabeth Barrichello

INSTITUICÃO ONDE SE REALIZARÁ A PESQUISA:

DATA DE ENTRADA NO CEP/UFTM:

PROTOCOLO CEP/UFTM:

sujeitos da pesquisa são avaliados uma única vez. Os estudos transversaís, também denominados seccionais, possuem vantagens pela rapidez, baixo custo, identificação de caso e deteç̧ão de grupos de risco, que são o foco do estudo (POLIT e HUNGLER, 2004

O local será uma instituição hospitalar pública em um município do interior de Minas Gerais, nos ambulatórios de cirurgias oncológicas.

\section{Instrumento de coleta de dados}

Para a obtenção dos dados serão usados dois instrumentos. O instrumento A foi elaborado para se obter as características sociais e clínicas dos sujeitos e a identificação de aspectos relacionados ao sono, não focalizadas no segundo instrumento (Apêndice 1).

Para avaliar a qualidade do sono nos pacientes em questão deste estudo, será utilizado um questionário denominado Índice de Qualidade do Sono de Pittsburg - PSQI (Anexo 1). Este instrumento foi desenvolvido e validado por Buysse et al (1989) e posteriormente traduzido e validado para o português (CEOLIN, 1999). O questionário contém dez questões, sendo que as questões número um, dois e três e quatro são abertas e as questões cinco, seis, sete, oito, nove e dez semi-abertas. Para todas as dez questões do questionário, há um espaço para registro dos comentários do entrevistado, se houver necessidade.

Para a entrevista, será solicitada aos sujeitos a anuência para participação no estudo, após terem sido esclarecidos sobre o tema, objetivo e finalidade do trabalho, bem como sobre a garantia do anonimato, sigilo e privacidade. Será solicitado por escrito o termo de Consentimento Livre e Esclarecido.

Análise dos dados

Para alcançar os objetivos 1, 2 e 3 será realizada uma análise descritiva dos dados, freqüências absolutas e percentuais, e os resultados serão representados por gráficos e tabelas.

\section{ADEQUAÇÃO DAS CONDIÇÕES}

A aplicação do questionário se fará em um local apropriado e adequado para a coleta de dados no próprio ambulatório da instituição.

\section{ANÁLISE DE RISCOS E BENEFÍCIOS}

Não há risco físico, o risco possivel refere-se à perda de confidencialidade. Para garantia do sigilo e anonimato, os participantes serão identificados através de códigos. O controle dos dados será de responsabilidade da pesquisadora. 


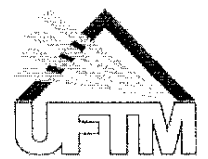

MINISTÉRIO DA EDUCAÇÃO

Universidade Federal do Triângulo MineIro - Uberaba(MG)

COMITÊ DE ÉTICA EM PESQUISA-CEP

Parecer Consubstanciado

PROTOCOLO DE PROJETO DE PESOUISA COM ENYOLVIMENTO DE SERES HUMANOS

Título Do PROJETO: Distúrbio nos padrões de sono em pacientes oncológicos

PESQUISADOR(A) RESPONSAVEL: Elizabeth Barrichello

INSTITUIČ̃̃ ONDE SE REALIZARÁ A PESQUISA:

DATA DE ENTRADA NO CEP/UFTM:

PROTOCOLO CEP/UFTM:

\section{RETORNO DE BENEFICIOS PARA O SUJEITO E/OU PARA A COMUNIDADE}

Quanto aos riscos, os entrevistados não estarão sujeitos a nenhum risco sendo resguardando a identidade dos sujeitos participantes em conformidade com a Lei 196/96. Será mantido o sigilo em relação à identidade dos entrevistados.

Em relação aos benefícios, espera-se contribuir para uma discussão e reflexão quanto ao distúrbio nos padrões do sono em pacientes oncológicos.

9. JUSTIFICATIVA DE SUSPENSÃO TERAPÊUTICA ("Wash out") - Não pertinente.

10. JUSTIFICATIVA DO USO DE PLACEBO - Não pertinente.

\section{ORÇAMENTO FINANCEIRO DETALHADO DA PESQUISA}

Papel chamex $=r \$ 100,00$; internet $=r \$ 25,00$; tinta para impressora $=r \$ 200,00$;

combustível $=r \$ 300,00$; canetas $=r \$ 10,00$; fotocópias/aquisição de livros $=r \$ 300,00$ total $=r \$$

935,00. o custeio será a partir do salário da pesquisadora.

12. FORMA E VALOR DA REMUNERAÇ̃̃O DO PESQUISADOR

O pesquisador recebe salário de professor assistente da UFTM

13. ADEQUAÇĀO DO TERMO DE CONSENTIMENTO E FORMA DE OBTÊ-LO

O termo de consentimento será apresentado pela pesquisadora envolvida no estudo. Os sujeitos assinarão o termo após esclarecimento, por livre arbítrio.

14. ESTRUTURA DO PROTOCOLO - O protocolo foi adequado para atender às determinações da Resolução CNS 196/96.

15. COMENTÁRIOS DO RELATOR, FRENTE À RESOLUÇÃO CNS 196/96 E COMPLEMENTARES

PARECER DO CEP: Aprovado

(O relatório anual ou final deverá ser encaminhado um ano após o início do processo). DATA DA REUNIĀO: 14-09-2007

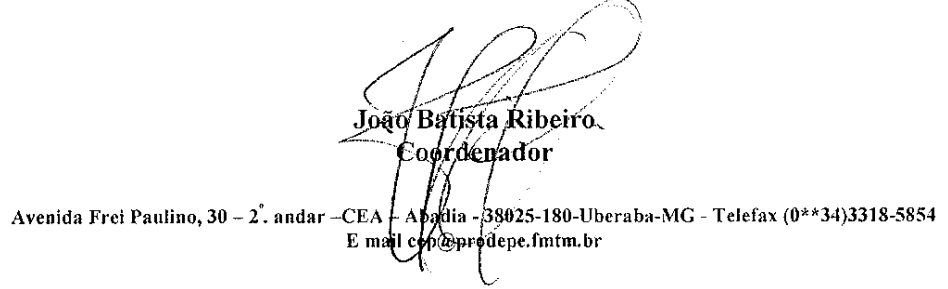


ANEXO B - Índice de Qualidade do Sono de Pittsburgh - PSQI

Nome: Sexo: ( ) M ( ) F

№ do RG:

DN: 1

Local da entrevista: DE:

Instruções:

As questões a seguir serão referentes aos seus hábitos de sono apenas durante o mês passado. Suas respostas devem indicar o mais corretamente possível o que aconteceu na maioria dos dias e noites do mês passado. Por favor, responda a todas as questões:

1- Durante o mês passado a que horas você foi deitar a noite, na maioria das vezes? HORÁRIO DE DEITAR:

Comentários do entrevistado (se houver):

2- Durante o mês passado, quanto tempo (em minutos) você demorou para pegar no sono, na maioria das vezes?

QUANTOS MINUTOS DEMOROU PARA PEGAR NO SONO:

Comentários do entrevistado (se houver):

3- Durante o mês passado, a que horas você acordou de manhã, na maioria das vezes?

HORÁRIO DE ACORDAR:

Comentários do entrevistado (se houver):

4- Durante o mês passado, quantas horas de sono por noite você dormiu? (Pode ser diferente do número de horas que você ficou na cama)

HORAS DE SONO POR NOITE:

Comentários do entrevistado (se houver):

Para cada uma das questões seguintes, escolha uma única resposta que você ache mais correta. Por favor responda a todas as questões. 
5- Durante o mês passado. Quantas vezes você teve problema para dormir por causa de:

(a) demorar mais de 30minutos (meia hora) para pegar no sono:

( ) nenhuma vez

menos de uma

Comentários do entrevistado (se houver):

(b) acordar no meio da noite ou de manhã muito cedo:

$\begin{array}{ll}\text { ( ) nenhuma vez } & \text { ( ) uma ou duas vezes por semana } \\ \text { ( ) menos de uma vez por semana } & \text { ( ) três vezes por semana ou mais }\end{array}$

Comentários do entrevistado (se houver):

(c) levantar-se para ir ao banheiro:

$\begin{array}{ll}\text { ( ) nenhuma vez } & \text { ( ) uma ou duas vezes por semana } \\ \text { ( ) menos de uma vez por semana } & \text { ( ) três vezes por semana ou mais }\end{array}$

Comentários do entrevistado (se houver):

(d) ter dificuldade para respirar:

( ) nenhuma vez ( ) uma ou duas vezes por semana

( ) menos de uma vez por semana ( ) três vezes por semana ou mais

Comentários do entrevistado (se houver):

(e) tossir ou roncar muito alto:

( ) nenhuma vez ( ) uma ou duas vezes por semana

( ) menos de uma vez por semana ( ) três vezes por semana ou mais

Comentários do entrevistado (se houver):

(f) sentir muito frio:

( ) nenhuma vez ( ) uma ou duas vezes por semana

( ) menos de uma vez por semana ( ) três vezes por semana ou mais

Comentários do entrevistado (se houver): 
(g) sentir muito calor:

$\begin{array}{ll}\text { ( ) nenhuma vez } & \text { ( ) uma ou duas vezes por semana } \\ \text { ( ) menos de uma vez por semana } & \text { ( ) três vezes por semana ou mais }\end{array}$

Comentários do entrevistado (se houver):

(h) ter sonhos ruins ou pesadelos:

( ) nenhuma vez ( ) uma ou duas vezes por semana

( ) menos de uma vez por semana ( ) três vezes por semana ou mais Comentários do entrevistado (se houver):

(i) outras razões por favor descreva:

(j) quantas vezes você teve problemas para dormir por esta razão, Durante o mês passado:

( ) nenhuma vez ( ) uma ou duas vezes por semana

( ) menos de uma vez por semana ( ) três vezes por semana ou mais Comentários do entrevistado (se houver):

6- Durante o mês passado, como você classificaria a qualidade do seu sono?

( ) muito boa

( ) menos de uma vez por semana

( ) ruim

( ) três vezes por semana ou mais Comentários do entrevistado (se houver):

7- Durante o mês passado, você tomou algum remédio para dormir, receitado pelo médico, ou indicado por outra pessoa ( farmacêutico, amigo, familiar) ou mesmo por sua conta?

( ) nenhuma vez

( ) menos de uma vez por semana ( ) três vezes por semana ou mais

Qual (is)?

Comentários do entrevistado (se houver):

8- Durante o mês passado você teve dificuldade de ficar acordado enquanto estava dirigindo, fazendo suas refeições ou participando de qualquer outra atividade social, quantas vezes isso aconteceu?

( ) nenhuma vez

( ) menos de uma vez por semana

( ) uma ou duas vezes por semana

( ) três vezes por semana ou mais 
Qual (is)?

Comentários do entrevistado (se houver):

9- Durante o mês passado você sentiu indisposição ou falta de entusiasmo para realizar suas atividades diárias?

( ) nenhuma indisposição nem falta de entusiasmo ( ) indisposição e falta de entusiasmo pequenas

( ) indisposição e falta de entusiasmo moderada ( ) muita indisposição e falta de entusiasmo

10- Para você o sono é:

( ) um prazer ( ) uma necessidade ( ) outro - Qual?

Comentários do entrevistado (se houver):

Você cochila? （） Sim （） Não

Comentários do entrevistado (se houver):

Caso sim, você cochila intencionalmente, ou seja, por que quer cochilar?

( ) Sim ( ) Não

Para você cochilar é:

( ) um prazer

( ) uma necessidade

( ) outro-Qual:

Comentários do entrevistado (se houver): 
ANEXO C: Índice de Qualidade do Sono de Pittsburg - Instruções de pontuação*

Componente 1: qualidade subjetiva do sono

Examine a questão 6 e atribua a pontuação da seguinte maneira:

\begin{tabular}{lc}
\multicolumn{1}{c}{ Resposta } & Pontuação \\
Muito boa & 0 \\
Boa & 1 \\
Ruim & 2 \\
Muito ruim & 3
\end{tabular}

Pontuação do componente 1:

Componente 2: latência do sono

1- examine a questão 2 e atribua a pontuação da seguinte maneira:

$\begin{array}{lc}\quad \text { Resposta } & \text { Pontuação } \\ \text { < ou }=15 \text { minutos } & 0 \\ 16-30 \text { minutos } & 1 \\ \text { 31- } 60 \text { minutos } & 2 \\ >60 \text { minutos } & 3\end{array}$

Pontuação do componente 2:

2- Examine a questão $5 a$ e atribua a pontuação da seguinte maneira:

Nenhuma vez

\section{Resposta}

Menos de $1 \mathrm{vez} / \mathrm{semana}$

1 a 2 vezes/semana

3 vezes/semana ou mais

\section{Pontuação}

0

1

2

3

Pontuação do componente 5a:

3- Some a pontuação da questão 2 e da questão 5a:

4- Atribua a pontuação do componente 2 da seguinte maneira:

Soma de 2 e 5a:

Soma de 2 e $5 a$

0

$1-2$

$3-4$

$5-6$
Pontuação do componente 2

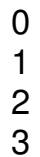

Pontuação do componente 2:

* Fonte (CUNHA, 2006). 
Componente 3: Duração do sono

1- Examine a questão 4 e atribua a pontuação da seguinte maneira:

$>7$ horas

Resposta

6-7 horas

$5-6$ horas

$<5$ horas

Pontuação
0
1
2
3

Componente 4: Eficiência Habitual do sono

Pontuação do componente 3:

1- Examine a questão 2 e atribua a pontuação da seguinte maneira:

(1) Escreva o número de horas dormidas (questão 4):

(2) Calcule o número de horas no leito:

Horário de levantar (questão 3) - horário de deitar (questão 1):

(3) Calcule a eficiência do sono:

$\left(\mathrm{N}^{\circ}\right.$ de horas dormidas $/ \mathrm{N}^{\circ}$ de horas no leito) $\times 100=$ eficiência do sono $(\%)$

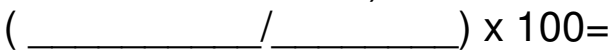
$\%$

(4) Atribua a pontuação do componente 4 da seguinte maneira:

$$
\begin{array}{r}
\text { Efici } \\
>85 \%
\end{array}
$$

$75-84 \%$

$65-74 \%$

$<65 \%$

Pontuação
0
1
2
3

Pontuação do componente 4:

Componente 5: Distúrbio do sono

1- Examine as questões de $5 b$ e $5 j$ e atribua a pontuação para cada questão, da seguinte maneira:

Nenhuma vez

Resposta

Menos de $1 \mathrm{vez} / \mathrm{semana}$

1 a 2 vezes/semana

3 vezes/semana ou mais

Pontuação
0
1
2
3

Some a pontuação de $5 b$ até $5 j$ :

3. Atribua a pontuação do componente 5 da seguinte maneira:

\begin{tabular}{|c|c|}
\hline & Pontuação \\
\hline 0 & 0 \\
\hline $1-9$ & 1 \\
\hline $10-18$ & 2 \\
\hline $19-27$ & 3 \\
\hline
\end{tabular}

Pontuação do componente 5: 
Componente 6: Uso de medicação para dormir

1- Examine a questão 7 e atribua a pontuação da seguinte maneira:

Nenhuma vez

Resposta

$<1 \mathrm{vez} / \mathrm{semana}$

1 a 2 vezes/semana

3 vezes/semana ou +
Pontuação

0

1

2

3

\section{Pontuação do componente 6:}

Componente 7: Sonolência diurna e distúrbios durante o dia

1- Examine a questão 8 e atribua a pontuação da seguinte maneira:

Nenhuma vez

Resposta

$<1 \mathrm{vez} / \mathrm{semana}$

1 a 2 vezes/semana

3 vezes/semana ou +

Pontuação
0
1
2
3

Pontuação da questão 8:

2- Examine a questão 9 e atribua a pontuação da seguinte maneira:

Nenhuma

Pequena

Moderada

Muita

Pontuação
0
1
2
3

Pontuação da questão 9:

3- Some a pontuação das questões 8 e 9:

4- Atribua a pontuação do componente 7 da seguinte maneira:

\begin{tabular}{|c|c|}
\hline Soma de 8 e 9 & Pontuação \\
\hline 0 & 0 \\
\hline $1-2$ & 1 \\
\hline $3-4$ & 2 \\
\hline $5-6$ & 3 \\
\hline
\end{tabular}

Pontuação do componente 7:

PONTUAÇÃO GLOBAL DO PSQI: 
ANEXO D - European Organization for Research and Treatment of Cancer Quality of Life Questionnaire “Core” 30 itens. (EORTC-QLQ-C30)

Iniciais do nome:

Data da coleta

Responda, por favor, a todas as perguntas fazendo um círculo no número que melhor se aplica a você. Não há respostas certas ou erradas. A informação que você fornecer permanecerá estritamente confidencial.

\begin{tabular}{|c|c|c|c|c|}
\hline & Não & Pouco & $\begin{array}{l}\text { Moderada- } \\
\text { mente }\end{array}$ & Muito \\
\hline $\begin{array}{l}\text { 1. Você tem qualquer dificuldade quando faz grandes } \\
\text { esforços, por exemplo carregar uma bolsa de compras } \\
\text { pesada ou uma mala? }\end{array}$ & 1 & 2 & 3 & 4 \\
\hline $\begin{array}{l}\text { 2. Você tem qualquer dificuldade, quando faz uma grande } \\
\text { caminhada? }\end{array}$ & 1 & 2 & 3 & 4 \\
\hline $\begin{array}{l}\text { 3. Você tem qualquer dificuldade quando faz uma curta } \\
\text { caminhada fora de casa? }\end{array}$ & 1 & 2 & 3 & 4 \\
\hline $\begin{array}{l}\text { 4. Você tem que ficar numa cama ou na cadeira durante o } \\
\text { dia? }\end{array}$ & 1 & 2 & 3 & 4 \\
\hline $\begin{array}{l}\text { 5. Você precisa de ajuda para se alimentar, se vestir, se } \\
\text { lavar ou usar o banheiro? }\end{array}$ & 1 & 2 & 3 & 4 \\
\hline \multicolumn{5}{|l|}{ DURANTE A ÚLTIMA SEMANA: } \\
\hline & Não & Pouco & $\begin{array}{l}\text { Moderada- } \\
\text { mente }\end{array}$ & Muito \\
\hline $\begin{array}{l}\text { 6. Você se sentiu limitado/a para realizar seu trabalho ou } \\
\text { cumprir suas atividades diárias? }\end{array}$ & 1 & 2 & 3 & 4 \\
\hline 7. Você se sentiu limitado/a em suas atividades de lazer? & 1 & 2 & 3 & 4 \\
\hline 8. Você teve falta de ar? & 1 & 2 & 3 & 4 \\
\hline 9. Você tem tido dor? & 1 & 2 & 3 & 4 \\
\hline 10. Você precisou repousar? & 1 & 2 & 3 & 4 \\
\hline 11. Você tem tido problemas para dormir? & 1 & 2 & 3 & 4 \\
\hline 12. Você tem se sentido fraco/a? & 1 & 2 & 3 & 4 \\
\hline 13. Você tem tido falta de apetite? & 1 & 2 & 3 & 4 \\
\hline 14. Você tem se sentido nauseado/a? & 1 & 2 & 3 & 4 \\
\hline
\end{tabular}

\section{DURANTE A ÚLTIMA SEMANA:}

15. Você tem vomitado?

16. Você tem ficado constipado?

17. Você tem tido diarréia?

18. Você esteve cansado/a?

19. A dor interferiu em suas atividades diárias?

20. Você tem tido dificuldade para se concentrar em coisas,

Não

Pouco

Moderada- Muito

mente como ler jornal ou ver televisão?

21. Você se sente tenso/a?

22. Você esteve preocupado/a?

23. Você se sentiu irritado/a facilmente?

24. Você se sentiu deprimido/a?

25. Você tem tido dificuldade para se lembrar das coisas?

26. A sua condição física ou o tratamento médico tem interferido em sua vida familiar? 
27. A sua condição física ou o tratamento médico tem interferido em suas atividades sociais?

28. A sua condição física ou o tratamento médico tem the 1 2 3 4 trazido dificuldades financeiras?

Para as seguintes perguntas, faça um círculo em volta do número entre 1 a 7 que melhor se aplica em você.

29. Como você classificaria a sua saúde em geral, durante a última semana?

$$
1
$$

$$
2
$$

3

4

5

6 7

Péssima

30. Como você classificaria a sua qualidade de vida global, durante a última semana?
1
2
3
4
5
6
7

Péssima

Ótima

Os número tem que ficar espalhados sendo o 1 em cima do $\mathbf{P}$ e o 7 em cima do 0 
ANEXO E - Escore e Pontuação do EORTC*

Estabelece-se um escore bruto (EB) de cada escala, que é formado pelo somatório do valor das alternativas assinaladas em cada questão/item que compõe a escala, e dividido pelo número de respostas. $O$ valor das alternativas varia de 1 a 4 , da questão 1 a 28.

$E B=q 1+q 2+q 3 \ldots \ldots \ldots q n / N$

Sendo que "N" é o número total dos itens que compõem a escala e o "n" ou item individual.

$E B=q 1+q 2+q 3 \ldots \ldots q n / N$

O segundo passo é a transformação linear (escore entre 0 a 100), que deve seguir os seguintes passos:

- Cálculo para as Escalas Funcionais:

Escore $=[(E B-1) /$ variação $] \times 100$

- Cálculo para a escala Global - EGS/QV:

Escore $=[(E B-1) /$ variação $] \times 100$

- Cálculo para as escalas/itens sintomas:

Escore $=[(E B-1) /$ variação $] \times 100$

${ }^{*}$ Fonte (KAMEO, 2006). 
O quadro 1 apresenta a estrutura do EORTC QLQ-30.

\begin{tabular}{|c|c|c|c|c|c|}
\hline & & \multicolumn{2}{|c|}{ Número } & \multicolumn{2}{|c|}{ Definição } \\
\hline Escalas* & Questões & Item & Níveis** & $\begin{array}{c}\text { Escore mínimo=0 } \\
\text { (floor) }\end{array}$ & $\begin{array}{c}\text { Escore máximo }=100 \\
\text { (ceiling) }\end{array}$ \\
\hline \multicolumn{6}{|c|}{ Medida Global de Saúde/QV } \\
\hline EGS & 29 e 30 & 2 & 6 & $\begin{array}{l}\text { Condição física } \mathrm{e} \\
\text { qualidade de vida ruins. }\end{array}$ & $\begin{array}{llr}\text { Condição } & \text { física } & \text { e } \\
\text { qualidade } & \text { de } & \text { vida } \\
\text { excelentes. } & & \\
\end{array}$ \\
\hline \multicolumn{6}{|c|}{ Escalas Funcionais } \\
\hline FF & 1 a 5 & 5 & 3 & $\begin{array}{l}\text { Confinado a cama, } \\
\text { necessita de ajuda para } \\
\text { tomar banho, vestir-se e } \\
\text { comer. }\end{array}$ & $\begin{array}{l}\text { Pode realizar atividades } \\
\text { físicas pesadas sem } \\
\text { dificuldade. }\end{array}$ \\
\hline DP & 6 e 7 & 2 & 3 & $\begin{array}{l}\text { Impedido de trabalho ou } \\
\text { realizar atividades de } \\
\text { lazer. }\end{array}$ & $\begin{array}{l}\text { Não apresenta limitações } \\
\text { no trabalho ou lazer. }\end{array}$ \\
\hline FE & 21 a 24 & 4 & 3 & $\begin{array}{l}\text { Sente-se muito tenso, } \\
\text { irritado, deprimido e } \\
\text { preocupado. }\end{array}$ & $\begin{array}{l}\text { Não se sente tenso, } \\
\text { irritado, deprimido e } \\
\text { preocupado. }\end{array}$ \\
\hline FC & 20 e 25 & 2 & 3 & $\begin{array}{lr}\text { Apresenta } & \text { muita } \\
\text { dificuldade } & \text { em } \\
\text { concentrar-se e recordar } \\
\text { informações. }\end{array}$ & $\begin{array}{lr}\text { Não } & \text { apresenta } \\
\text { dificuldades } & \text { de } \\
\text { concentração e memória. }\end{array}$ \\
\hline FS & 26 e 27 & 2 & 3 & $\begin{array}{l}\text { A condição física e o } \\
\text { tratamento interferem } \\
\text { muito na vida familiar e } \\
\text { em atividades sociais. }\end{array}$ & $\begin{array}{l}\text { A condição física e o } \\
\text { tratamento não interferem } \\
\text { na vida familiar e nas } \\
\text { atividades sociais. }\end{array}$ \\
\hline \multicolumn{6}{|c|}{ Escalas de Sintomas } \\
\hline FAD & 10,12 e 18 & 3 & 3 & $\begin{array}{l}\text { Não se sente cansado } \\
\text { ou fraco e não necessita } \\
\text { descansar. }\end{array}$ & $\begin{array}{l}\text { Sente-se muito fraco, } \\
\text { cansado e necessita } \\
\text { descansar a maior parte } \\
\text { do tempo. }\end{array}$ \\
\hline NAV & 14 e 15 & 2 & 3 & $\begin{array}{l}\text { Não apresenta náuseas } \\
\text { ou vômitos }\end{array}$ & $\begin{array}{l}\text { Sente-se muito nauseado } \\
\text { e vomita muito. }\end{array}$ \\
\hline Dor & 9 e 19 & 2 & 3 & Não sente dor. & $\begin{array}{l}\text { Apresenta muita dor que } \\
\text { interfere em todas as } \\
\text { atividades. }\end{array}$ \\
\hline \multicolumn{6}{|c|}{ Sintomas (itens) } \\
\hline DIS & 8 & 1 & 3 & Não apresenta dispnéia. & $\begin{array}{l}\text { Apresenta } \\
\text { severa. }\end{array}$ \\
\hline INS & 11 & 1 & 3 & $\begin{array}{l}\text { Não tem dificuldades } \\
\text { para dormir. }\end{array}$ & Não consegue dormir. \\
\hline PAP & 13 & 1 & 3 & Apetite conservado & Anorexia severa. \\
\hline $\mathrm{CON}$ & 16 & 1 & 3 & Sem constipação & Constipação severa. \\
\hline DIA & 17 & 1 & 3 & Sem diarréia. & Diarréia severa. \\
\hline \multicolumn{6}{|l|}{ Item } \\
\hline DIF & 28 & 1 & 3 & 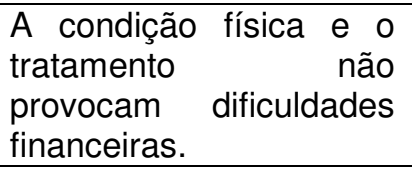 & $\begin{array}{lr}\text { A condição física e o } \\
\text { tratamento } & \text { provocam } \\
\text { muitas } & \text { dificuldades } \\
\text { financeiras. } & \\
\end{array}$ \\
\hline
\end{tabular}

* Siglas das Escalas: EGS= Estado Geral de Saúde/QV; FF= Função Física; DP= Desempenho de Papel; $F E=$ Função Emocional; $F C=$ Função Cognitiva; $F S=$ Função Social; $F A D=$ Fadiga; $N A V=$ Náuseas e Vômitos; DIS= Dificuldades Financeiras. ${ }^{* *}$ Diferença entre a maior e a menor resposta possível de cada item.

Quadro 1 - Escalas e itens do EORTC QLQ-30, questões correspondentes, numero de itens e variação de cada item. 